Published in "Chemistry - A European Journal 26(48): 10948-10971, 2020" which should be cited to refer to this work.

\title{
Handling (Nano)Silver as Antimicrobial Agent: Therapeutic Window, Dissolution Dynamics, Detection Methods and Molecular Interactions
}

\author{
Sarah-Luise Abram and Katharina M. Fromm*[a]
}

\begin{abstract}
Silver is an antimicrobial agent well known since antiquity. With the emergence of multiresistant bacteria, it has come back into the focus of research, and ionic as well as nano-sized silver have been studied in vitro and in vivo. The results are controversial, silver being discussed as the "silver bullet" or a "wolf in sheep's clothing". A thorough search of literature from chemistry, materials and environmental science, biology and medicine led to this Review which summarizes the potential use of silver and its com-
\end{abstract}

pounds in medicine, ongoing processes of dissolution and the different methods by which this usefulness can be evaluated. It also highlights the therapeutic window of silver, mechanistic interactions of silver and biological media as well as best practices for handling silver in a biomedical environment. This Review reflects the current knowhow and observations, and may thus give hints and guidelines to understand and interpret the observed effects. 


\section{Introduction}

One of the most frightening global health threats is the rapid development and spreading of microbial resistance to antibiotics leading to the inability to treat infection diseases, but also adding risks to many other medical treatments that require surgery or immune suppression. ${ }^{[1]}$ The WHO warns already against the imminent accession into a post-antibiotic era if no solution to this problem is found. ${ }^{[2]}$ Already now 50000 people are estimated to die each year from antimicrobial-resistant infections in the EU and US, a number that is predicted to rise to over 10 million worldwide in 2050. ${ }^{[1]}$ Despite increasing global awareness and action plans ${ }^{[3]}$ emphasizing the importance of a large reduction in the use of antibiotics, the antibiotic consumption is still increasing (by $65 \%$ between 2000-2015 expressed as defined daily doses). ${ }^{[4]} \mathrm{New}$ classes of antibiotics are unlikely to be available for the clinics soon. ${ }^{[5]}$ The shorter the time that the microorganisms need for resistance development the lower is the profit a pharmaceutical company can earn with the development of a new drug. ${ }^{[6]}$ This impedes the commercial research and development of new antibiotics.

Currently, new antimicrobial drugs and drug delivery systems are developed on the basis of nanotechnology with a strong focus on metal-based systems $(\mathrm{Cu}, \mathrm{Ag}, \mathrm{Zn}){ }^{[7]}$ They are chosen for their broad range of antimicrobial activity at relatively low doses that are well tolerated in humans. Moreover, they are relatively cheap, offer long-term efficiency and are easy to integrate into nanomaterials and nanocomposites. The use of Ag for its antimicrobial activity is not new but nowadays the advances in nanotechnology allow for the production of well-defined nanoparticles and the precise control of the physicochemical properties at the nanoscale leading to a higher bioactivity than bulk materials. ${ }^{[7]}$ Moreover, nanotechnology

[a] Dr. S.-L. Abram, Prof. K. M. Fromm

Department of Chemistry

University of Fribourg

Chemin du Musée 9, 1700 Fribourg (Switzerland)

E-mail:Katharina.fromm@unifr.ch

(iD The ORCID identification number(s) for the author(s) of this article can be found under:

https://doi.org/10.1002/chem.202002143.

Part of a Special Issue for the 8th EuChemS Chemistry Congress consisting of contributions from selected speakers and conveners. To view the complete issue, visit lssue 48 offers ways to design multifunctional materials that can comprise diagnostic tools, targeting of specific biological sites, and different therapeutic agents. An exponential rise since the early years of 2000 and more than 1000 publications in 2014 show the potential of $\mathrm{Ag}$ as part of the solution to the antimicrobial resistance crisis. ${ }^{[8]}$ For these reasons, nano-antimicrobials turn out to be of particular value for the prevention of localized or topical infections in the form of wound dressings or implant coatings. Thus, the next sections will provide insight into the challenge of biomaterial-related infections and nanosilver-based drugs as a potential solution.

\subsection{Biomaterials}

According to IUPAC a biomaterial is defined as a "material exploited in contact with living tissues, organisms, or microorganisms". ${ }^{[9]}$ Williams gave in 2009 a narrower definition: "A biomaterial is a substance that has been engineered to take a form which, alone or as part of a complex system, is used to direct, by control of interactions with components of living systems, the course of any therapeutic or diagnostic procedure, in human or veterinary medicine."[10] In the past decades, prolonged life expectancies have led to an increased use of biomaterials as natural tissue repair mechanisms start to fail more frequently at high age. Tumor excisions, repair after severe trauma or natural attrition of joints all require the use of biomaterials to restore the function of the affected body part. Thus, their use contributes to the objective of healthy ageing with the replacement of degenerated joints in osteoarthritis patients being one of the most obvious examples. One can distinguish permanently implanted materials, such as artificial joints, artificial heart valves, vascular prostheses, or dental implants, and temporary devices that support healing (pulmonary assist device, urinary or intravenous catheters). Used in medicine for more than 70 years, their introduction meant a breakthrough in many medical fields, for example, in the treatment of bone fractures with the help of fixation devices that enabled healing of the bone in the optimal position. ${ }^{[11]}$ While in early days, materials such as Pyrex, Bakelite or Vitallium have been tested as biomaterials, nowadays, a great variety of metallic, polymeric, ceramic or composite materials is used, sometimes even biologically derived, such as blood vessel scaffolds. ${ }^{[11]}$ The biocompatibility of the implant describes the reactions of the host tissue to the biomaterial. In contrast to vascularized tissue 
or vital cells, biomaterials are usually accepted by the immune system without immune suppression, even if inflammation processes, toxic or mutagenic effects, allergic reactions or infections can occur as negative consequences of biomaterial usage. ${ }^{[11]}$

\subsection{Implant-associated infections}

Biomaterial surfaces are not equipped with natural antibiotics and hence attract microorganisms, leading to infection incidences of $0.1 \%$ (contact lenses) to $16 \%$ (abdominal wall patch) over lifetime, and $25 \%$ per month for voice prostheses and $33 \%$ per week for catheters. ${ }^{[12]}$ In a "race to the surface", bacterial and tissue cells compete in adhering to the implant surface. ${ }^{[13]}$ If bacteria win this race, an infection results and the biomaterial is not well integrated into the host tissue. Infection rates reaching $7.4 \%$ and $10.4 \%$ for total knee and hip replacement in $1971,{ }^{[14]}$ the infection rate for such surgery is still at $0.5-2 \%$ today. ${ }^{[15]}$ The rates vary depending on the type of material and the body part that the implant is replacing. ${ }^{[12]}$ As the use of biomaterials increases, also the total number of infections rises which correlates with a significant increase in the costs for health care systems.

Implant associated infections are categorized according to the time of their occurrence: early infections happen within less than three months after surgery, delayed infections within 3-24 months after surgery and late infections occur even more than two years after surgery. ${ }^{[15 b]}$ The latter are induced by the hematogenous route, whereas early and delayed infections are aroused by bacteria present during the operation or entering the wound before healing ("exogenous infections"). Early infections often involve virulent strains while later infections are also caused by organisms with lower virulence. ${ }^{[11]}$ The pathogens found in periprosthetic joint infections are mainly coagulase-negative Staphylococci such as S. aureus, with the fraction of MRSA varying among different countries. ${ }^{[16]}$ Also non-pathogenic bacteria can sometimes cause implant infections, for example, Propionibacterium acnes. ${ }^{[11]}$ Polymicrobial infections occur in $14 \%$ of cases, ${ }^{[16]}$ while $5 \%$ of the periprosthetic joint infections are reported to be culture-negative and dependent on the antibiotic pretreatment and on how careful the culture techniques are carried out. ${ }^{[17]}$

While the implants can be often preserved in the case of hematogenous infections of less than three week duration and early infections less than one month after surgery, ${ }_{1}^{[1]]}$ chronic implant infection requires the removal of all foreign material, as the formed bacterial biofilm is not susceptible to antibiotic treatment. In repeated surgeries, the implant has to be replaced after the infection has cleared and the initial costs of an implantation are then tripled. ${ }^{[12]}$

As few as 100 cfu (colony forming units) of S. aureus are sufficient to induce an infection in the presence of biomaterials, ${ }^{[18]}$ while more than the 100000 -fold is necessary without implants present. ${ }^{[19]}$ For hematogenous seeding, a bacteremia level of $10^{3} \mathrm{cfumL}^{-1}$ blood was enough to colonize $42 \%$ of the implanted cages. ${ }^{[20]}$ Truly sterile conditions are impossible to accomplish, and it was estimated that ca. 270 bacteria per $\mathrm{cm}^{2}$ and hour contaminate the wound during surgery. ${ }^{[21]}$ The high prevalence (19\%) of $P$. acnes in shoulder arthroplasty infections suggests that such infections originate from the patient's own microbiome as this bacterium belongs to the microbiome of the shoulder region. ${ }^{[22]}$

The choice of the material does not necessarily influence the risk of infection. ${ }^{[11]}$ In vitro studies revealed an increased biofilm formation on titanium compared to stainless steel ${ }^{[23]}$-a difference that could not be confirmed in vivo. ${ }^{[24]}$ These findings are comprehensible as proteins such as fibronectin, fibrinogen or laminin directly coat any implant surface as soon as it gets in touch with the tissue during surgery. These proteins are known to support cell attachment, no matter if it is bacterial cells or host tissue. ${ }^{[11]}$

Besides successful tissue integration, a quick immune response based on phagocytosis of the bacteria by macrophages and granulocytes present in tissues around implants prevent implant infections. ${ }^{[25]}$ Zimmerli et al. reported that granulocytes around a subcutaneous implant in an animal model did not efficiently kill Staphylococci, even though the opsonization of the bacteria had taken place. ${ }^{[19]}$ In vitro, a process called "frustrated phagocytosis" ${ }^{126]}$ occurs, which means that the contact with the non-phagocytosable implant surface activates the granulocytes indicated by continuous production of reactive oxygen species (ROS) and release of specific granules. ${ }^{[27]}$ The presence of the foreign body and the surgical trauma thus compromise the immune response. The immune system is additionally challenged by the presence of wear particles from the implant. ${ }^{[28]}$ In the presence of polymeric particles, neutrophil granulocytes partly lost their antimicrobial activity. Thus, cytokines released 
by macrophages upon phagocytosis of wear particles can induce implant loosening due to bone resorption by osteoclasts. ${ }^{[29]}$

\subsection{Biofilms}

The main reason for the high persistence of implant-associated infections is the formation of biofilms on the implant surface. When bacteria adhere to the implant surface, they form microcolonies of numerous cells, which produce an extracellular matrix (slime) made of exopolysaccharides, DNA and proteins. This structure is called biofilm and can act like a multicellular organism. ${ }^{[30]}$ The biofilm develops in several stages: (1) initial attachment (arrival of the first cells of planktonic origin), (2) irreversible attachment: adhesion of the cells and beginning of extracellular matrix production, (3) Maturation I: exponential growth of the adherent cells protected by their slime, (4) Maturation II: beginning of nutrient deficiency in the center, and (5) dispersion. Biofilms offer mechanical protection, act as a reservoir for extracellular enzymes and enable the establishment of long-term synergistic relations between the bacterial cells like in a multicellular organism. ${ }^{[30,32]}$ The biofilm helps in the transfer and switching on or off of genes and the regulation of pili, flagella and exopolysaccharides during maturation. ${ }^{[31]} \mathrm{A}$ quorum sensing (QS) system is responsible for the production and release of virulence factors that help the biofilm to persist. ${ }^{[32]}$ This chemical communication between the cells is correlated to the population density and triggers processes that are inefficient for single cells but beneficial for a larger number of cells, for example, for nutrition and oxygen supply to inner cells, also during periods with low nutrients, temperature variations, $\mathrm{pH}$ changes, exposure to antimicrobials, or damaging irradiation.

Biofilms resist to the immune response of the host as well as to antibiotic treatment because of the low penetration of the antibiotics and the high diversity of the bacterial cells inside the biofilm. Indeed, lack of nutrients and oxygen sets bacteria into a dormant state with low metabolic activity ("persisters") that protects these bacteria from uptake of antibiotics. ${ }^{[33]}$ Two concentration gradients delay delivery and further impede antibiotic uptake: first from the blood stream to the host tissue and secondly from the host tissue to the biofilm, allowing for an efficient enzymatic degradation of antibiotics by bacteria in the biofilm. ${ }^{[33,34]}$ Two classes of antibiotics have shown activity against biofilms: rifampin and rifamycin for Staphylococci and fluoroquinolones against Gram-negative bacteria. ${ }^{[11]}$

\subsection{Implant protection}

Zimmerli summarized current research strategies against implant associated infections as follows: $:^{[11]}$ (1) vaccination against antigens synthesized during biofilm formation; (2) development of inhibitors of bacterial QS, and (3) antimicrobial coatings.

While it is still unclear if QS-inhibiting drugs are really beneficial in biofilm combat, biomaterial coatings could be achieved with antimicrobial peptides, traditional antibiotics, disinfectants or antimicrobial metals, such as $\mathrm{Ag}, \mathrm{Cu}$ or $\mathrm{Zn}$. Problems arise however from high regulatory barriers. ${ }^{[11,12]}$ Surgical meshes or tibial nails with gentamicin integrated into a biodegradable matrix or antibiotic releasing bone cements are among examples that were successfully translated into clinics and typically last a few days. ${ }^{[35]}$ Temporary devices can be coated with nonadhesive, antibiotic releasing, silver-impregnated or contactkilling coatings. ${ }^{[12]}$ For permanent devices, surface properties that enable fast adhesion of the host cells are attractive solutions, but also favor microbial attachment. Thus, multifunctional coatings are thus needed that provide adhesive sites for the host cells and nonadhesive sites for bacterial cells which can be achieved due to the differences in the size of both cell types. ${ }^{[36]}$ An antimicrobial coating should not impair the immune response, support the tissue integration while killing all present microorganisms, no matter if in active or dormant state, and should last at least for 2-3 weeks after surgery. Yet, long-term protection would be desirable, just as well as appropriate methods for their in vitro evaluation.

Requirements are different for revision surgery, for which higher infection rates are usually observed. ${ }^{[12,37]}$ Indeed, bacteria survive in the peri-implant tissue, ${ }^{[38]}$ inside osteoclasts, osteoblasts or macrophages. ${ }^{[39]}$ Thus, applied antibiotics should also exhibit activity against such intracellular species.

In order to mimic the "race to the surface", bacteria and tissue cells need to be cultured together, either in a static or flow system, and relevant cell lines as well as microbial strains should be chosen depending on the specific implant type, as the design of the in vitro experiments severely influences the results. ${ }^{[12]}$ For instance, antibiotic containing bone cements show biofilm growth under flow conditions and inhibition without it. ${ }^{[40]}$ Therefore, the microbial strains and the experimental conditions, such as growth media or the presence of certain proteins should be carefully chosen in order to avoid bias. ${ }^{[12]}$ Co-culturing of bacterial cells and eukaryotic cells are still challenging, as the growth medium has to offer conditions favorable for both types of cells, and needs further validation. ${ }^{[41]}$ First results have shown that from a certain coverage with mammalian cells, bacterial attachment can be impaired, ${ }_{1}^{[42]}$ but upon co-culturing host cells with S. aureus, the bacterial cells adhere preferably, and thus faster. ${ }^{[41 a]}$

Testing antimicrobial coatings in vivo in (small) animals is problematic as their immune response is largely different from the one in humans, and bacterial challenges have to be adjusted according to the animal. Only subcutaneous implants are tested due to the small animal size, which complicates any implantation at the real implant site and does not reliably answer the question by how much biomaterial related infections would be reduced in clinical application. For translation into commercial applications, human clinical trials would be necessary, but due to the low infection rates of only a few percent, they require a too large number of patients to prove a statistically significant reduction of the infection rates. ${ }^{[12]}$ 


\section{Ag as an Antimicrobial Agent}

\subsection{General applications of nanosilver}

Silver nanoparticles (AgNPs) are used in numerous commercial products leading to a production of several hundred tons of nanosilver per year with the expectation to increase dramatically. ${ }^{[43]}$ They are used for their excellent broad-spectrum antimicrobial properties in medical applications (catheters, implant surfaces, plasters, wound dressings) and consumer products (clothes, toys, household goods, disinfectants, water treatment, paints, mobiles phones, washing machines, or refrigerators), ${ }^{[4]}$ but also in catalysis or imaging and immune-detection due to their surface-enhanced Raman scattering (SERS) effect, where the Raman scattering signal of a molecule adsorbed to the AgNP surface is significantly enhanced due to excitation of localized surface plasmons. ${ }^{[45]}$ Moreover, applications are reported in the electronics field as transparent conducting films, electrodes for flexible devices or in solar cells. ${ }^{[46]}$ According to "The Silver Institute", a silver industry association, 93-311 tons of Ag are annually used for the production of antimicrobial coatings, with a double-digit growth predicted for the next 510 years. ${ }^{[47]}$ However, the more the Ag technology is evolving and used in consumer products, the higher is the potential environmental exposure and spreading of $\mathrm{Ag}$, emphasizing the need of thorough risk assessment. A permanent release into waste water from textiles, ${ }^{[48]}$ deodorants and cosmetics, washing machines, ${ }^{[49]}$ outdoor paints, ${ }^{[50]}$ or disposal of other products might also be dangerous for the bacterial population in sewage treatment plants. ${ }^{[46]}$ Hazards for human health depend on the possible exposure routes: inhalation of AgNPs from sprays ${ }^{[51]}$ skin exposure through cosmetics, ${ }^{[52]}$ or direct contact to damaged tissue by wound dressings ${ }^{[53]}$ or implant coatings.

\subsection{Applications of $\mathrm{Ag}$ in medicine}

The knowledge about the beneficial health effects of Ag dates back to ancient Egypt and Rome ${ }^{[46]}$ Ayurvedic medicine in India, ${ }^{[54]}$ and traditional Chinese medicine. ${ }^{[55]}$ Silver coins have for instance been used to preserve drinking water or milk from microbial contamination. ${ }^{[56]}$ In 1954 , silver was registered in the US as biocidal material, but colloidal nanosilver suspensions have already been used commercially at the end of the 19th century and beginning of 20th century, for example, as Collargol, Argyrol or Protargol for treatment of bacterial infections (e.g. syphilis) ${ }^{[57]}$ Nowadays, the interest in silver as antimicrobial agent recurs in the context of the increasing resistance of pathogens to the antibiotics developed throughout the 20th century. ${ }^{[58]}$ Such multidrug resistant microbes are surprisingly susceptible to $\mathrm{Ag}$ as its antimicrobial action is based not only on a single mechanism. ${ }^{[59]}$ Another advantage of $\mathrm{Ag}$ in medical products is the high temperature stability in contrast to organic antibiotics which enables for instance easy processing for composite materials. ${ }^{[57]}$ Silver can be used for its biocidal properties in form of salts, complexes, or nanoparticles with a great variety of shapes (spheres, rods, wires, cubes, and triangles), sizes or coatings (e.g. citrate, polymers, peptides, and sugars).
Some applications in the medical field are already well established with wound dressings especially for burn wounds being the most advanced product; but also surgical meshes, vascular prosthesis, ventricular drainage catheters and orthopedic implant coatings based on Ag technology are already in clinical use. ${ }^{[60]}$ Despite the long-term application in medicine, there is an ongoing debate about the risks, benefits and biological mechanisms of nanosilver as antimicrobial product. In this context, Reidy et al. stressed the importance of sufficient characterization of the studied AgNPs. ${ }^{[46]}$ As particles are subjected to changes and ageing under physiological conditions, their interaction and toxicity might also alter over time, which complicates the clarification of mechanisms. Detailed characterization and description of the investigated NP systems, the used experimental conditions, and the changes of NPs in the used biological solutions, at the relevant temperatures and over the experiment time scale are thus necessary to develop structureactivity correlations and to ensure comparability between different studies.

\subsection{Biological properties: How do AgNPs interact with bio- logical systems?}

The biological activity of nanosilver has to be reflected in the context of the Ag speciation in an aqueous colloidal suspension. Compared to Ag bulk materials such as macroscopic foils or Ag bars, the specific surface area of AgNPs is dramatically increased, which leads to a higher dissolution of ionic $\mathrm{Ag}^{+} .^{[61]}$ For this reason, the biological effects of nanosilver can be attributed to surface reactions of AgNPs, but also to $\mathrm{Ag}^{+}$ions or soluble $\mathrm{Ag}^{+}$complexes. Toxicity pathways of nanoparticles are controversially discussed in the literature, particularly with regard to the attribution to ions, particles or combined impacts like the Trojan horse effect. ${ }^{[62]}$ Through this effect, very high $\mathrm{Ag}^{+}$concentrations can be reached locally as AgNPs transport a high silver amount to sensitive target sites by attachment to the bacterial membrane or by endocytosis before degrading at these locations. ${ }^{[62 b, 63]}$ For bacterial targets, this mechanism supports the view of AgNPs as drug delivery system for toxic $\mathrm{Ag}^{+}$ions. ${ }^{[61 \mathrm{~b}]}$ The surface reactions of AgNPs include the formation of ROS, catalytic oxidation of cellular compounds, and adsorption of biomolecules like proteins, enzymes, or DNA, thus restraining their function. Similar effects result from the binding of $\mathrm{Ag}^{+}$ions to the functional groups (e.g. amine or thiol moieties) of biologically relevant molecules. The binding to the thiol groups of intracellular ROS scavengers like glutathione (GSH) unbalances for instance the intracellular redox levels. ${ }^{[61 \mathrm{~d}]}$

\subsubsection{Prokaryotic cells}

The antimicrobial effects of Ag seem to be independent of the bacterial strain. This broad-spectrum antibiotic activity, taken together with the activity against antibiotic resistant strains, ${ }^{[64]}$ explains the high interest in antimicrobial Ag materials. ${ }^{[65]}$ In general, we distinguish Gram-positive and Gram-negative bacterial strains, which differ in the construction of their cell walls. 
Gram-positive bacteria possess a single membrane covered with a thick, multilayered peptidoglycan layer. Their cell wall contains $20-40$ wt $\%$ teichoic acids which are not present for Gram-negative strains. Instead, the cell wall of a Gram-negative organism is composed of two membranes with a thin layer of peptidoglycan in between. Despite the presence of two membranes, it is much thinner than the cell wall of Gram-positive bacteria. Several studies have reported a higher activity level of $\mathrm{Ag}$ against Gram-negative strains compared to Gram-positive ones, claiming that the latter are better protected by the thick peptidoglycan layer. ${ }^{[66]}$ Investigation of the impact of $\mathrm{Ag}^{+}$ on the bacterial cells by electron microscopy showed indeed less destruction for S. aureus than for E. coli. ${ }^{[67]}$

The minimum inhibitory concentration (MIC) as well as the bactericidal concentrations (MBC) of different ionic and nanosilver systems for a great variety of Gram-positive and Gramnegative bacterial isolates have been reported and will here serve as exemplary active concentration ranges. ${ }^{[64]}$ Figure 1 shows the $\mathrm{MIC}_{90}$ values for the used materials for the four subgroups of MDR (multi-drug resistant) Gram-positive, MDR Gram-negative, antimicrobial-susceptible Gram-positive and antimicrobial-susceptible Gram-negative strains. The $\mathrm{MIC}_{90}$ corresponds to the MIC for $90 \%$ of the isolates for a certain species or subgroup. The values are comprised between 6.75 and $\geq 54 \mu \mathrm{g} \mathrm{mL}^{-1} \mathrm{Ag}$. The meta-analysis of available nanosilver MICs/MBCs by Chernousova and Epple results in a similar range of $0.1-20 \mu \mathrm{g} \mathrm{mL}^{-1}$. ${ }^{[6]}$

The antimicrobial mechanism of silver was already summarized in several reviews. ${ }^{[46,61 c, 69]} \mathrm{Ag}^{+}$and AgNPs mainly interact with bacterial membrane proteins. ${ }^{[69 a]}$ The binding of $\mathrm{Ag}^{+}$to sulfur by replacing the proton in thiol groups blocks the bacterial respiratory chain, thus interfering with electron transport and ATP production. ${ }^{[70]}$ The inhibition of ATP synthase as one of the main proteins of the respiratory chain leads to lower levels of ATP inside the cells and a dissipation of the proton motive force. ${ }^{[71]}$ Consequently, the metabolism of the cell is reduced and the permeability and damage of the membrane increases as it cannot resist the external osmotic pressure resulting in leakage of cellular components and finally cell death. ${ }^{[8]}$ Membrane disruption can be promoted by $\mathrm{Ag}^{+}$as it supports

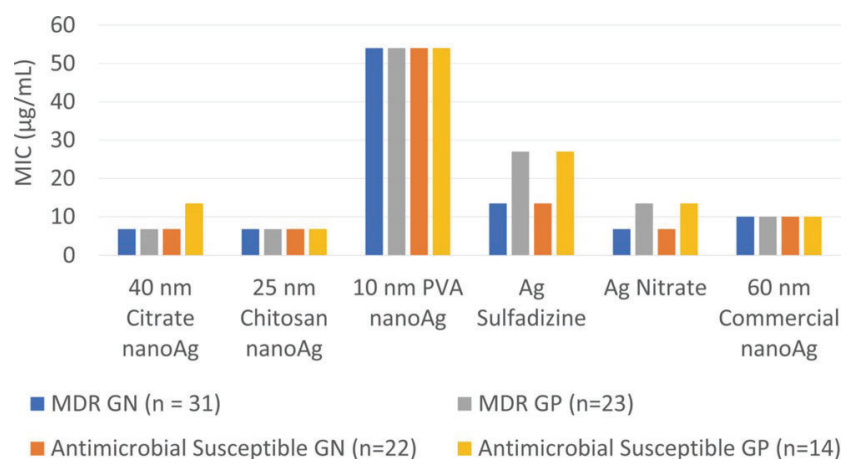

Figure 1. MIC $C_{90}$ for AgNPs capped by citrate, PVP, or chitosan and silver sulfadiazine, silver nitrate and commercial AgNPs as controls for comparing the tested MDR and antimicrobial-susceptible Gram-positive and Gram-negative isolates. Adapted from ref. [64], licensed under CC BY 4.0. the breaking of $\beta-1-4$ glycosidic bonds between peptidoglycan blocks. ${ }^{[72]}$ Moreover, the locally lower $\mathrm{pH}$ at the outer side of the membrane (as low as $\mathrm{pH}$ 3.0) could enhance the dissolution of AgNPs. ${ }^{[73]}$ The uptake of $\mathrm{Ag}^{+}$ions into the bacterial cell was shown to happen already after only $30 \mathrm{~min}$ of incubation. ${ }^{[7]}$ Once the membrane is disrupted, $\mathrm{Ag}^{+}$can enter even more easily into the cytoplasm where it can bind the thiol or amine groups of other proteins, changing their conformation and thus impairing their function, especially for enzymes. ${ }^{[75]}$ One of its main intracellular targets are bacterial ribosomal proteins with their denaturation leading to the inhibition of protein biosynthesis. ${ }^{[74]}$ Moreover $\mathrm{Ag}^{+}$can interact with nucleic acids preferring the nucleosides over the phosphate groups and thus hindering DNA replication. ${ }^{[70 a]}$ Another important toxicity mechanism of $\mathrm{Ag}$ species is the generation of ROS. ${ }^{[7]}$ High ROS levels were found inside and outside the cells and can also result from cell damage or the breaking of the respiratory chain. ${ }^{[61 b]}$ Antioxidative enzymes might not be able to regulate the ROS levels as their activity is known to depend on thiol groups, which are blocked by the $\mathrm{Ag}^{+}$. Choi and Hu were able to correlate the toxicity of $\mathrm{Ag}^{+}, \mathrm{AgCl}$ and $\mathrm{AgNPs}$ to the intracellular ROS levels in nitrifying bacteria (Figure 2). ${ }^{[7]} \mathrm{Kim}$ et al. showed a drastic decrease in antimicrobial efficacy by addition of $\mathrm{N}$-acetylcysteine (NAC) as an antioxidant, supporting thus the importance of ROS in the antimicrobial mechanism of action. ${ }^{[78]}$ Besides the release of $\mathrm{Ag}^{+}, \mathrm{AgNPs}$ also contribute to the antimicrobial effects by adhering to and altering the bacterial membrane proteins and leading to structural damage and increased permeability. ${ }^{[46,60,69 a, c]}$ If particles penetrate the membrane, the same effects account for interaction with intracellular biomolecules and DNA resulting in condensed substance seen as electron-light regions in the center of the cell by

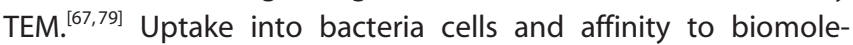
cules depend on the size, surface charge and functionalization. ${ }^{\text {[79a] }}$ Generally, the antimicrobial mechanisms might change with particle size und surface properties. Particles with high ion release could act similar to $\mathrm{Ag}^{+}$, while for larger ones, or very small, or positively charged ones, particle related mechanisms could dominate. ${ }^{[61 c, 80]}$

\subsubsection{Mammalian cells}

Unlike prokaryotic bacterial cells, mammalian cells contain a variety of membrane-bound structures, called organelles, for example, a nucleus that encloses most of the genetic material or mitochondria that are, inter alia, responsible for the supply with cellular energy. In general, these eukaryotic cells are much bigger than prokaryotes with up to the 10000 -fold volume. Toxicity measurements for these cell types look at changes in the cell morphology, at the generation of ROS, the metabolic activity and/or the expression of stress markers. ${ }^{[54]}$ The cell lines for in vitro experiments should be chosen corresponding to the potential target sites of toxicity. These depend on the biodistribution of NPs in the organism, which can be determined in vivo. Experiments with rats report the accumulation of AgNPs in the lung after inhalation but also their transport into the liver and gastrointestinal tract. ${ }^{[81]}$ After entry into the 
A

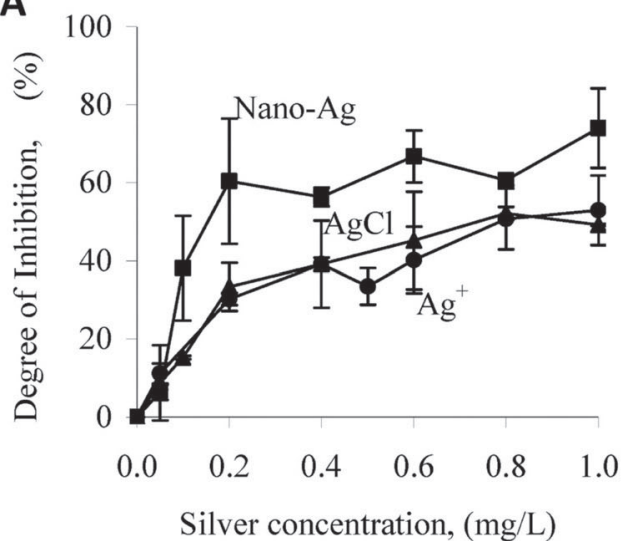

B

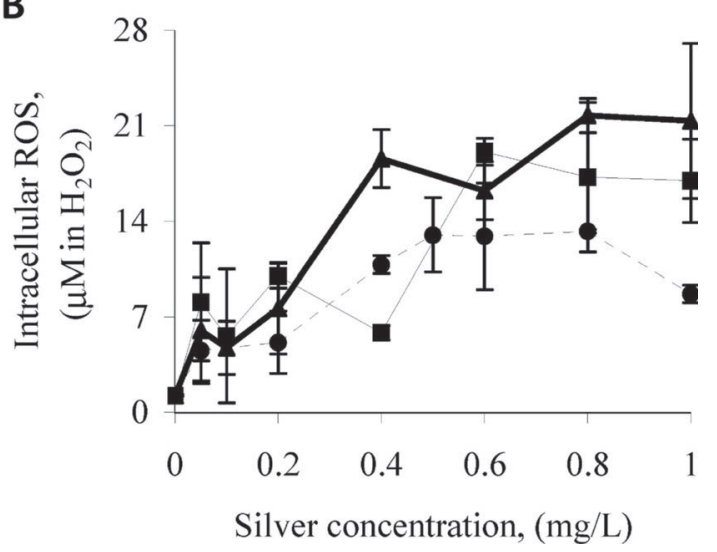

Figure 2. Inhibition of nitrifying bacteria by $15 \mathrm{~nm}$ AgNPs (squares), $250 \mathrm{~nm}$ AgCl NPs (triangles) and $\mathrm{Ag}^{+}$(circles). (A) Degree of nitrification inhibition with increasing concentrations, (B) Correlation of intracellular ROS levels with the administered silver concentration. Reprinted with permission from ref. [77]. Copyright 2008, American Chemical Society.

body, AgNPs are able to cross the blood-brain barrier. ${ }^{[82]}$ Intravenous injections into rats showed accumulation in all organs (spleen, liver, lungs, and kidney) with a lower accumulation for the smallest tested size $(20 \mathrm{~nm}){ }^{[83]}$ Such injection studies can give an impression of potential targeted tissues but they neglect that the change of the particle protein corona with the exposure route can also influence the later biodistribution and toxicity. ${ }^{[46,84]}$ As typical exposure routes comprise penetration through the skin, inhalation, and ingestion, liver or lung cell lines are often chosen for studies that presume inhalation as major exposure route. Human mesenchymal stem cells are essential in wound healing and tissue regeneration and thus involved for Ag applications in wound dressings and implant coatings, as are fibroblasts and osteoblasts.

The exposure of AgNPs to mammalian cells is reported to induce dose-dependent oxidative stress, inflammatory, genotoxic, and cytotoxic responses. Weak points of many studies comprise a lack of time-resolved toxicity data, insufficient differentiation between ionic and particulate Ag species, and the application of excessively high, irrelevant doses. ${ }^{[46]}$ The already mentioned meta-analysis by Chernousova and Epple reports a toxic concentration range of $1-10 \mu \mathrm{gL}^{-1}$ for $\mathrm{Ag}^{+}$ions and 10-100 $\mathrm{g} \mathrm{mL}^{-1}$ for AgNPs. ${ }^{[68]}$ The toxicity studies summarized in a review by Rai et al. provide an overview on the potential cytotoxic effects, ${ }^{[54]}$ whereas Foldbjerg et al. review in detail the cellular and molecular mechanisms behind AgNP toxicity. ${ }^{[61 d]}$ Kaur and Tikoo found generation of ROS, cellular disruption, and increased expression of stress markers (pp38, TNF- $\alpha$, HSP-70) in skin or lung epithelial cells and murine macrophages after exposure of $5-100 \mu \mathrm{g} \mathrm{mL}^{-1}$ AgNPs. ${ }^{[85]}$ For murine macrophages, the uptake of AgNPs was observed via scavenger receptor mediated phagocytosis and confirmed by microscopy. ${ }^{[86]}$ The authors report mitochondrial damage leading to apoptosis and cell death, which they trace back to the release of $\mathrm{Ag}^{+}$being 50 times faster in the cytoplasm than in water. Grosse et al. emphasized the accumulation of AgNPs on the cells damaging their membranes. ${ }^{[87]}$ Sur et al. found the toxicity to be surface chemistry related: citrate-coated AgNPs were more toxic than lactose or oligonucleotide functionalized particles. ${ }^{[8]}$ The localization of AgNPs after uptake into cells is reported differently: they are mainly found in endosomal/lysosomal structures, ${ }^{[61 d, 89]}$ but also evenly distributed in the cytoplasm and nucleus, ${ }^{[00]}$ eventually with resulting DNA damaging. ${ }^{[91]}$ Braydich-Stolle et al. observed also an impact on spermatogonial stem cells provoking the question of potential side effects on reproductive and developmental processes. ${ }^{[89]}$

Also the inflammatory response is controversially discussed. Yen et al. compared AgNPs to AuNPs of similar size and found upregulation for TNF- $\alpha$, IL-1, and IL-6 for Au but not for Ag. ${ }^{[92]}$ The authors suggest the different charge and the different uptake pathway as potential reasons for the different responses. In contrast, Trickler et al. suggest a dose and size dependent proinflammatory response for AgNPs. ${ }^{[93]}$

Besides the cytotoxicity against mammalian cells, researches also investigate the ecotoxicology, usually finding very low toxic concentrations in the range of a few micrograms per liter. ${ }^{[75 b, 80 b]}$ One of the key mechanisms for the toxicity against fish and invertebrates is the blocking of the gill $\mathrm{Na}^{+}, \mathrm{K}^{+}$-adenosine triphosphatase resulting in a too low uptake of $\mathrm{Na}^{+}{ }^{[94]}$

\subsubsection{Antiviral and other biological properties}

In addition to the antimicrobial activity, Ag has also antifungal, antiviral, antiplatelet and anti-inflammatory effects that might be further exploited in Ag-nanomedicine. ${ }^{[46]}$ In wound dressing applications, the beneficial effects comprise not only the antimicrobial properties, but also the support of healing via the promotion of proliferation and migration of keratinocytes, the reduction of collagen formation, and the modulation of cytokine production. ${ }^{[60]}$ Moreover, studies suggested a slight hormetic effect of AgNP and $\mathrm{AgNO}_{3}$ towards prokaryotic and eukaryotic cells. ${ }^{[95]}$ Sublethal concentrations of both, $\mathrm{AgNO}_{3}$ and NPs significantly increased the bacterial viability of an E. coli strain compared to the control with no $\mathrm{Ag}{ }^{[73]}$

The antiplatelet effect of nanosilver serves as an example for the interaction of AgNPs with proteins. AgNPs can prevent 
blood coagulation by slowing down the polymerization of fibrinogen, most probably due to inhibition of the enzymatic activity of thrombin. ${ }^{[96]}$

Antiviral properties were shown against a broad range of virus families: retroviridae, hepadnaviridae, paramyxoviridae, herpesviridae, poxviridae, okthomyxoviridae and arenaviridae. ${ }^{[97]}$ Rai et al. review the antiviral activities against human immunodeficiency virus, Hepatitis B virus, influenza virus, Herpes simplex virus, and poxvirus among others. ${ }^{[54]}$ Again, there are few chances for resistance due to multiple ways of interaction either with the viral surface itself or with the host cell membrane receptors. ${ }^{[54]}$ Metal NPs can inhibit the viral replication inside the host cell, block the entry of the virus particle into the host cell, destroy the viral envelope or bind to viral coating proteins. Also, the combination of NPs with existing virucidal or virustatic compounds could be a promising strategy to enhance their activity. Given their unspecific antiviral response, Ag or other metal NPs are not limited to a certain virus family, which is of importance in clinical cases concerning unknown viruses.

\subsection{Therapeutic window}

Recently, more and more studies are trying to cover both, cytotoxicity and antimicrobial activity, targeting at the determination of a therapeutic window. Albers et al. compared the cytotoxicity of various forms of silver (NPs, microparticles, $\mathrm{Ag}^{+}$) on osteoblasts and osteoclasts with the antimicrobial effect on S. epidermidis. ${ }^{[98]}$ The amounts needed for antimicrobial activity were found to be 2-4 times higher than the cytotoxic ones, questioning the safe use of nanosilver coatings on implant materials. Chernousova and Epple emphasized that the toxic concentration ranges for prokaryotic and eukaryotic cells are overlapping, limiting the therapeutic window. ${ }^{[68]}$ These results are substantiated by a study of the same group comparing the toxic concentrations against human mesenchymal stem cells (hMSCs), peripheral blood mononuclear cells, E. coli, and S. aureus, using the same culture medium (RPMI/ $10 \%$ FCS). ${ }^{[99]}$ RPMI was chosen for mimicking the in vivo conditions of the potential antimicrobial application in a better way than bacterial growth media. Moreover, the used AgNPs show colloidal stability in RPMI whereas they agglomerate and precipitate in lysogeny broth (LB) medium. Table 1 shows how small the therapeutic window is, which was also confirmed in a study by Jain et al. ${ }^{[100]}$ Yet, Epple and co-authors mention as well several studies of polymer-Ag composites and films that have bactericidal effects without harming mammalian cells. ${ }^{[99]}$ Determination of the effective Ag concentrations for comparison is however difficult.
Hrkac et al. could show that the therapeutic window increases dramatically on an Ag containing surface. ${ }^{[101]}$ They compared the bacterial and fibroblast growth on a surface in the presence of dissolved silver nitrate and on $\mathrm{TiO}_{2}$ coatings with varying $\mathrm{Ag} \%$. For $\mathrm{Ag}^{+}$solutions, they found only a very narrow therapeutic window whereas for the coatings, the window was much larger (Figure 3). By comparison with an $\mathrm{Ag}^{+}$release experiment, they found coherence to the fibroblast toxicity but not to the bactericidal concentrations suggesting an increased antimicrobial effect happening at the surface. Similar results were reported with AgNPs immobilized on functionalized glass slides, exhibiting a better antimicrobial activity than firstly, the same mass of colloidal AgNPs, and secondly, a pure Ag plate, despite the Ag plate showing a higher $\mathrm{Ag}^{+}$release. ${ }^{[102]}$

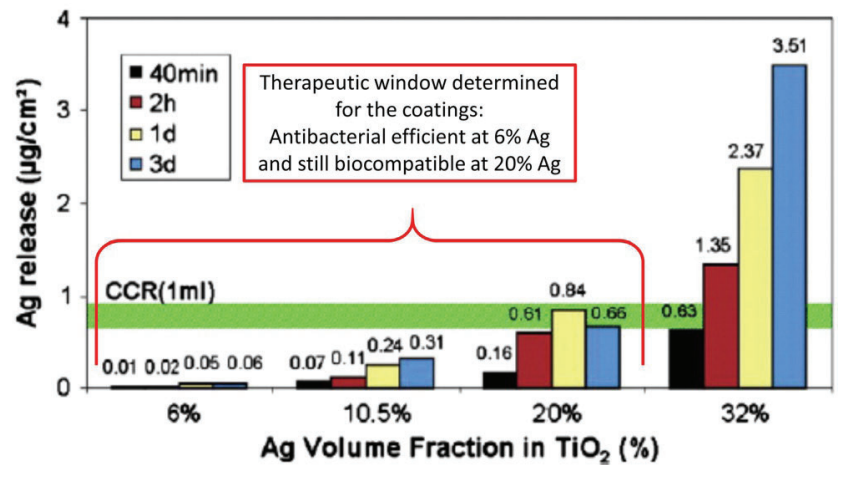

Figure 3. Increased therapeutic window for Ag containing surface coatings: Cumulative $\mathrm{Ag}^{+}$release from $\mathrm{Ag}-\mathrm{TiO}_{2}$ surface coatings with increasing $\mathrm{Ag}$ content. The green bar represents the therapeutic window determined with silver nitrate using the same experimental setup as for the surfaces. Adapted with permission from ref. [101]. Copyright 2013, Elsevier.

Another recent study by Kaiser et al. reports the dependence of the toxic concentrations on the media composition (chloride, organic compounds) and on cell culture conditions. ${ }^{[103]}$ They found no toxicity towards Caco-2 cells when they used floating cell culture with the cells hanging upside down into the medium, when cells were exposed only to the dissolved/ dispersed Ag-species in the upper part of the well. In contrast, cells grown at the bottom of the well were highly affected by the same silver dose. It is thus difficult to compare experiments with eukaryotic cells attached on the well bottom to experiments with planktonic bacterial cells for the determination of a therapeutic window.

\subsection{Dissolution of Ag nanoparticles}

Despite the ongoing controversy about the mechanisms of nanosilver toxicity, the release of $\mathrm{Ag}^{+}$ions as active species

\begin{tabular}{|c|c|c|c|c|c|}
\hline & $\begin{array}{l}\text { E. coli } \\
{\left[\mathrm{MBC}, 10^{3} \text { cfu mL }{ }^{-1}\right]}\end{array}$ & $\begin{array}{l}\text { S. aureus } \\
\left.\mathrm{MBC}, 10^{3} \mathrm{cfu} \mathrm{mL}^{-1}\right]\end{array}$ & T-cells & Monocytes & hMSCs \\
\hline $\mathrm{Ag}^{+}\left[\mu \mathrm{g} \mathrm{mL}^{-1}\right]$ & 0.5 & 1.25 & 1.5 & 1 & 2.5 \\
\hline $70 \mathrm{~nm}$ AgNPs $\left[\mu \mathrm{g} \mathrm{mL}^{-1}\right]$ & 12.5 & 20 & $>50$ & 30 & 50 \\
\hline
\end{tabular}


seems to be central. The dissolution kinetics of a given nanosilver sample influence the antimicrobial activity, eukaryotic toxicity as well as the environmental impact and persistence, emphasizing thus the importance of understanding this phenomenon. As many other metal ions used in NPs are already known to be toxic (e.g. $\mathrm{Zn}^{2+}, \mathrm{Cu}^{2+}, \mathrm{Cd}^{2+}$ ), researchers addressing NP toxicity are trying to differentiate between NP-specific mechanisms and the impact of ions that dissolved from them, ${ }^{[104]}$ in order to develop nanosilver systems with controlled $\mathrm{Ag}^{+}$release and safe biological activity.

To be released as $\mathrm{Ag}^{+}$ions, the $\mathrm{Ag}$ atoms of the AgNPs need to be oxidized first. The oxidation/dissolution rate depends on physicochemical properties of the AgNPs (intrinsic factors, such as shape, size, crystallinity or surface coatings) as well as on the composition of the solution (extrinsic factors such as ionic strength, $\mathrm{pH}$, dissolved oxygen concentration, temperature and complexing ligands or precipitating anions). ${ }^{[44]}$ Size is controlled by the kinetics of precipitation and growth, whereas the shape is influenced by the number and distribution of twins within the particle and the growth kinetics along different crystallographic axis. ${ }^{[4]]}$ The surface chemistry is determined by the capping ligands used in the synthesis and can be altered by ligand exchange processes. The extrinsic factors depend on the used setup in the release experiment or the final application.

\subsubsection{Dissolution mechanisms}

The release of $\mathrm{Ag}^{+}$ions is believed to take place via the intermediate formation of $\mathrm{Ag}_{2} \mathrm{O}$ on the surface of the AgNPs by dissolved oxygen or hydrogen peroxide as oxidizing agents. ${ }^{[105]}$ Hydrogen peroxide is formed as metabolic product by many living organisms. It is also postulated to form as intermediate during the dissolution of AgNPs. Concentrations of $0.4 \mu \mathrm{M}$ $\mathrm{H}_{2} \mathrm{O}_{2}$ were detected by $\mathrm{Ma}$ et al. during the dissolution of citrate capped AgNPs in air saturated water at $\mathrm{pH} 8{ }^{\left[{ }^{[99]}\right.} \mathrm{Liu}$ and Hurt proved the evolution of ROS by performing peroxide sensitive fluorescence assays with the $\mathrm{Ag}^{+}$containing supernatant of their dissolution experiment. ${ }^{[106]}$ The first oxidation step of the AgNPs leads to a core-shell structure with a metallic Ag core and a thin $\mathrm{Ag}_{2} \mathrm{O}$ shell. ${ }^{[105 a, 107]}$ The dissolution of this shell releases the $\mathrm{Ag}^{+}$ions, thus exposing again metallic $\mathrm{Ag}$ that is oxidized again to $\mathrm{Ag}^{\prime}$ oxide [Eqs. (1) and (2)]: ${ }^{[107,108]}$

$$
\begin{aligned}
& 4 \mathrm{Ag}(\mathrm{s})+\mathrm{O}_{2} \rightarrow 2 \mathrm{Ag}_{2} \mathrm{O}(\mathrm{s}) \\
& \mathrm{Ag}_{2} \mathrm{O}+\mathrm{H}_{2} \mathrm{O} \rightarrow 2 \mathrm{Ag}^{+}+2 \mathrm{OH}^{-}
\end{aligned}
$$

or including the intermediate formation of various ROS [Eq. (3)]: ${ }^{[61 b]}$

$$
\mathrm{Ag}+\mathrm{O}_{2} \rightarrow \mathrm{Ag} \cdots \mathrm{O}_{2} \underset{-\mathrm{Ag}^{+}}{\stackrel{n \mathrm{H}^{+}}{\longrightarrow}} \text { R.O.I. } \stackrel{3 \mathrm{Ag}+(4-n) \mathrm{H}^{+}}{\longrightarrow} 3 \mathrm{Ag}^{+}+2 \mathrm{H}_{2} \mathrm{O}
$$

in which R.O.I. = reactive oxygen intermediates. Several studies proved that the presence of oxygen is necessary for the $\mathrm{Ag}$ dissolution to occur as no measurable $\mathrm{Ag}^{+}$release was detect- ed in deoxygenated water (Figure 4B). ${ }^{[106,109]}$ Sotiriou et al. investigated the dissolution of AgNPs before and after an additional reduction step with $\mathrm{H}_{2}$ and found significantly reduced amounts of released $\mathrm{Ag}^{+}$after $\mathrm{H}_{2}$ treatment. ${ }^{[105 a]}$ They could quantify the released silver to correspond to 1-2 atomic layers of oxidized silver on the NP's surface. All release was finished within $2 \mathrm{~h}$ and could not be triggered again by removal of the released fraction. Pretreatment of AgNPs with ozone was reported to significantly increase the $\mathrm{Ag}^{+}$ion release rate, but also changed the release profile introducing a sharper burst release compared to the non-treated samples, which corresponded most probably to the dissolution of the preformed oxide layer. $^{[61 \mathrm{~b}]}$

The mechanism via the formation of $\mathrm{Ag}_{2} \mathrm{O}$ is moreover consistent with the increased dissolution rate under acidic conditions, as protons are needed for the dissolution of $\mathrm{Ag}_{2} \mathrm{O}$ [Eq. (3)]. Liu and Hurt followed the pH rise expressed in Equation (2) during their dissolution experiments. ${ }^{[106]} \mathrm{pH}$ dependent release experiments revealed the importance of protons during the release mechanism. Figure $4 \mathrm{D}$ compares the released fraction of $2 \mathrm{mg} \mathrm{mL}^{-1}$ AgNP-suspensions after one day at different $\mathrm{pH}$ values. Less $\mathrm{Ag}^{+}$ions are released at $\mathrm{pH} 9$ than in deoxygenated water at $\mathrm{pH} 4$, as confirmed by Peretyazhko et al. ${ }^{[108]}$

The oxidative dissolution is a thermodynamically favored process at room temperature, and for environmentally or biologically relevant conditions, $\mathrm{Ag}^{+}$ions are the only existing species in thermodynamic equilibrium. ${ }^{[106]} \mathrm{The}^{\mathrm{Ag}^{+}}$ion release from Ag colloids is kinetically controlled and the complete dissolution is hardly observed. Among others, Kittler et al. and Peretyazhko et al. determined the dissolution to follow pseudo first order kinetics [Eq. (4)], ${ }^{[45,108]}$ the rate constant $k$ being affected by intrinsic and extrinsic factors.

$\left[A g^{+}\right]_{t}=\left[A g^{+}\right]_{t \rightarrow \infty}(1-\exp (-k t))$

in which $\left[\mathrm{Ag}^{+}\right]_{t}\left[\mathrm{Ag}^{+}\right]_{t \rightarrow \infty}$ are the concentration of $\mathrm{Ag}^{+}$released at a certain time $t$ and at $t \rightarrow \infty$, respectively. Several research groups studied the $\mathrm{Ag}^{+}$release at different temperatures revealing higher $\mathrm{Ag}^{+}$release for higher temperatures, ${ }^{[45]}$ for example, $4.8 \pm 1.6 \mathrm{~nm}$ citrate-capped AgNPs released ca. $20 \%$ at $4{ }^{\circ} \mathrm{C}$, ca. $50 \%$ at $20^{\circ} \mathrm{C}$ and ca. $90 \%$ at $37^{\circ} \mathrm{C}$ after one day (Figure 4). ${ }^{[106]}$ The time needed for complete dissolution depended also on their initial concentration and varied from about one week ( $0.05 \mathrm{mg} \mathrm{L}^{-1}$ AgNP) to more than 3 months ( $2 \mathrm{mg} \mathrm{L}^{-1}$ AgNPs). Addition of these AgNPs to a $\mathrm{AgClO}_{4}$ solution resulted in an initial decrease of the free $\mathrm{Ag}^{+}$concentration and an increase of the particle surface charge (zeta potential). These findings suggest that free $\mathrm{Ag}^{+}$ions adsorbed on the NP surface. ${ }^{[106]}$

In contrast, dialysis experiments with $50 \pm 20 \mathrm{~nm}$ AgNPs in concentration ranges of $50-350 \mathrm{mg} \mathrm{L}^{-1}$ never reached a full dissolution. ${ }^{[45]}$ The authors concluded that neither the released $\mathrm{Ag}^{+}$concentration nor the amount of available oxygen (in excess) are the decisive factors for the observed release kinetics, but that the limiting value is an inherent characteristic of a certain nanosilver system. Another study on the incomplete 

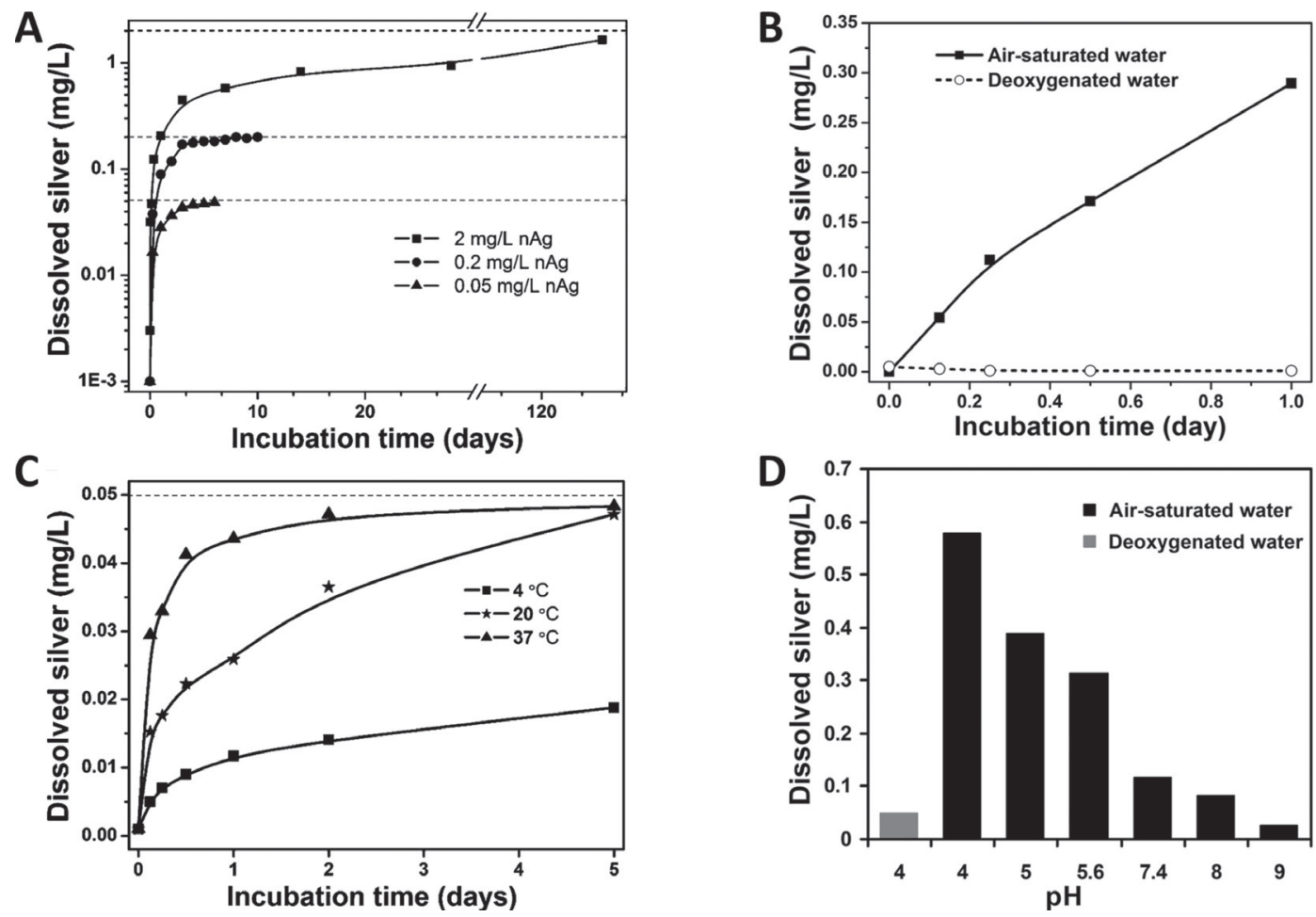

Figure 4. $\mathrm{Ag}^{+}$release experiments with $4.8 \mathrm{~nm}$ citrate capped AgNPs by Liu and Hurt: (A) concentration dependence, (B) oxygen dependence, (C) temperature dependence, and (D) pH dependence (one day released fraction). Reprinted with permission from ref. [106]. Copyright 2010, American Chemical Society.

dissolution of $\mathrm{AgNPs}^{[75 \mathrm{~b}]}$ found that the dissolved $\mathrm{Ag}^{+}$concentration rose within $6 \mathrm{~h}$ and reached an equilibrium concentration after $24 \mathrm{~h}$, which was relatively higher for lower starting AgNP concentrations. The extent of release furthermore changed significantly under real toxicological experiment conditions.

Despite the different time frames needed for reaching an equilibrium concentration (minutes ${ }^{[105 a]}$ until months ${ }^{[45]}$ ) and the different $\mathrm{Ag}^{+}$concentration ranges $\left(\mu \mathrm{M}^{[99,108]}-\mathrm{mM}^{[105 a]}\right)$, the release profile is similar with a fast initial burst release followed by a slower phase, that stabilizes finally at a certain $\mathrm{Ag}^{+}$concentration. Molleman and Hiemstra offered a mechanistic explanation by introducing the formation of subvalent $\mathrm{Ag}$ species on the surface of AgNPs as a consequence of surface oxidation. ${ }^{[110]}$ First, they claim that $\mathrm{Ag}_{2} \mathrm{O}$ cannot form a stable coating layer on a metallic $\mathrm{Ag}^{0}$ surface due to the longer $\mathrm{Ag}$ Ag distances in $\mathrm{Ag}_{2} \mathrm{O}$ compared to metallic Ag. Moreover, such $\mathrm{Ag}_{2} \mathrm{O}$ would dissolve immediately upon contact with water, which is inconsistent with most release experiments. ${ }^{[111]}$ For these reasons, they proposed the formation of subvalent groups $\left(\mathrm{z}_{\mathrm{Ag}}=+1 / 3\right)$ such as $\equiv \mathrm{Ag}_{3} \mathrm{OH}^{0}$ and the more stable octahedral species $\equiv \mathrm{Ag}_{6} \mathrm{O}^{0}$ on the AgNP surface, deduced from structures that can be found in Ag minerals. ${ }^{[110]}$ Their calculations and observations resulted in Equations (5), (6) and (7):

starting reaction: $\equiv \mathrm{Ag}_{3} \mathrm{OH}^{0}+\mathrm{O}_{2}+3 \mathrm{H}^{+} \Leftrightarrow 3 \mathrm{Ag}^{+}+2 \mathrm{H}_{2} \mathrm{O}+\mathrm{O}^{\circ}$ circular reactions involving ROS for excess release :

$\mathrm{O} \cdot+\mathrm{H}_{2} \mathrm{O} \Rightarrow \mathrm{H}_{2} \mathrm{O}_{2}$

$\equiv \mathrm{Ag}_{3} \mathrm{OH}^{0}+\mathrm{H}_{2} \mathrm{O}_{2} \Leftrightarrow 3 \mathrm{Ag}^{+}+3 \mathrm{OH}^{-}+\equiv \mathrm{Ag}_{3}^{0}$

$\mathrm{Ag}_{3}^{0}+\mathrm{O}_{2}+\mathrm{H}^{+}+\mathrm{H}_{2} \mathrm{O} \Leftrightarrow \equiv \mathrm{Ag}_{3} \mathrm{OH}^{0}+\mathrm{H}_{2} \mathrm{O}_{2}$

final reaction stabilizing the AgNP surface against further oxidation $\equiv \mathrm{Ag}_{6}^{0}+\mathrm{O}^{\circ} \Leftrightarrow \equiv \mathrm{Ag}_{6} \mathrm{O}^{0}$

The surface $\equiv \mathrm{Ag}_{3} \mathrm{OH}^{0}$ groups are oxidized by molecular oxygen setting free an oxygen radical [Eq. (5)] which can either react immediately with the underlying bare $\mathrm{Ag}^{0}$ layer to form the stable octahedral $\equiv \mathrm{Ag}_{6} \mathrm{O}^{0}$ species [Eq. (7)] or cause more $\mathrm{Ag}^{+}$release by a circular reaction [Eq. (6)]. These equations explain the restart of oxidative dissolution upon dilution of AgNP suspensions. A layer of oxidized Ag would kinetically protect AgNPs against full oxidation". ${ }^{[110]}$ In a refined model, they introduced $\equiv \mathrm{Ag}_{5}(\mathrm{OH})_{2}$ as second relevant surface species besides $\equiv \mathrm{Ag}_{3}(\mathrm{OH})$ and identified two $\mathrm{pH}$-dependent mechanistic pathways for silver ion release: ${ }^{[111]}$ The first one, fully described with a thermodynamic and a kinetic Langmuir model, involves the equilibration of the two subvalent surface species initiated by dilution. The second pathway covers the fast $\mathrm{Ag}^{+}$release at low $\mathrm{pH}$ where dissolution of $\equiv \mathrm{Ag}_{3}(\mathrm{OH})$ is much faster than the formation of $\equiv \mathrm{Ag}_{5}(\mathrm{OH})_{2}$, thus creating patches of dissolution that grow laterally until full layers are removed. With increasing $\mathrm{Ag}^{+}$concentration, patch formation is stopped, so this mecha- 
nism is limited to the first day. Figure 5 summarizes this mechanistic model, allowing for the complete interpretation of the $\mathrm{pH}$, size and time dependency of the $\mathrm{Ag}^{+}$release data for citrate-capped AgNPs.

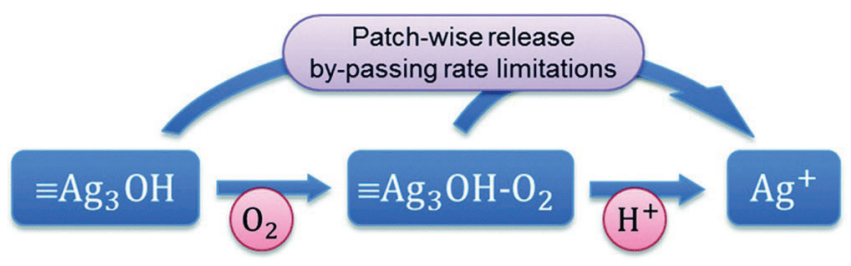

Figure 5. Scheme of the $\mathrm{Ag}^{+}$release mechanism proposed by Molleman and Hiemstra. At high $\mathrm{pH}$ the $\mathrm{H}^{+}$concentration is rate limiting, at lower $\mathrm{pH}$ the $\mathrm{O}_{2}$ adsorption is rate limiting. Reproduced with permission from ref. [111]. Copyright 2017, The Royal Society of Chemistry.

As all proposed mechanisms are surface processes, smaller AgNPs dissolve faster than the larger ones, due to their high surface-to-volume ratio. Indeed, the surface of smaller particles contains more atoms at corners or edges and gaps in the crystal lattice leading to a more reactive surface and thus to a higher release. ${ }^{[4]}$ These trends have been confirmed in several studies with particles over a wide size range ${ }^{[68,132]}$ for example, by $\mathrm{Ma}$ et al. who found only $1 \%$ released from $80 \mathrm{~nm}$ particles over three months compared to $60 \%$ for $5 \mathrm{~nm} .{ }^{[12]}$ While a piece of $\mathrm{Ag}$ foil dissolves at a five orders of magnitude lower rate than NPs, ${ }^{[68]}$ normalization to the surface area diminished these differences to less than one order of magnitude. Hence, correlations should be drawn between dissolution and surface area rather than simple NPs size. However, since the surface area is analytically not accessible in the suspended state, it is calculated from the size and can be highly imprecise for polydisperse samples. ${ }^{[46]}$

\subsubsection{Influence of the surface ligands and solution composi- tion}

Remaining capping ligands on the NP surface due to wetchemical synthesis will influence the Ag dissolution and interact with the released $\mathrm{Ag}^{+}$ions. Different surface coatings can also alter the aggregation and like that the $\mathrm{Ag}^{+}$ion release. As the release into ultrapure water is a highly unrealistic scenario for real applications and environmental risk assessment, experiments in ultrapure water are only helpful to deduce the mechanism of oxidative dissolution and the impact of single intrinsic factors. Biomolecules with functional groups are able to coordinate the released $\mathrm{Ag}^{+}$ions, while anions can lead to precipitation of insoluble $\mathrm{Ag}^{+}$salts. The ionic strength of such media can also alter the dispersion stability and thus, for example, via the formation of aggregates, the amount of released $\mathrm{Ag}^{+}$. Especially chloride as well as thiol groups in biological media are major sinks for the free $\mathrm{Ag}^{+}$concentration. Only at very high concentrations of chloride, soluble $\mathrm{AgCl}_{x}^{(x-1)-}(\mathrm{aq}, x=1-4)$ species form and increase the total amount of dissolved $\mathrm{Ag}^{+}$.
Such $\mathrm{Cl}^{-}$concentrations occur for example, in mitochondria, the cytoplasm, extracellular spaces, or seawater. ${ }^{[46]}$ Levard et al. investigated the influence of sodium chloride and showed that the $\mathrm{Ag}^{+}$ion release from PVP capped $33 \mathrm{~nm}$ AgNPs in HEPES buffer is reduced below the level of the control in $\mathrm{DI}$ water until a $\mathrm{Cl} / \mathrm{Ag}$ ratio of 2675 (Figure 6). ${ }^{[113]}$ A significant change of the zeta potential to more negative values supports that the released $\mathrm{Ag}^{+}$precipitated in form of $\mathrm{AgCl}$ or nucleated as $\mathrm{AgCl}$ onto the AgNPs below this ratio, while soluble $\mathrm{AgCl}_{x}^{(x-1)-}$ species dominate the equilibrium at higher chloride levels. The dissolved fraction after 12 days of ageing in presence of different $\mathrm{Cl}^{-}$concentrations shows a similar trend (Figure 6B). Antimicrobial testing of these aged suspensions against $E$. coli revealed a clear correlation of the toxicity and the soluble fraction, corroborating that the chloride concentration is a prominent factor regulating the biological impact of AgNPs in absence of thiols or sulfides. In another study however, the $\mathrm{AgCl}$ particles were not found on the AgNPs, but always separately as new particles. ${ }^{[109]}$ The binding constant to sulfide species is so high $\left(\log K=13\right.$ for $\mathrm{Ag}^{+}$and $\mathrm{HS}^{-}$) that in presence of excess sulfides, their $\mathrm{Ag}^{+}$complexes will form preferentially. ${ }^{[114]}$ This is of importance for the $\mathrm{Ag}^{+}$speciation under environmental conditions as excess sulfides and hence precipitation as $\mathrm{Ag}_{2} \mathrm{~S}$ decrease the toxicity significantly. ${ }^{[115]} \mathrm{AgCl}$ particles could be dissolved completely by addition of GSH as model for thiol
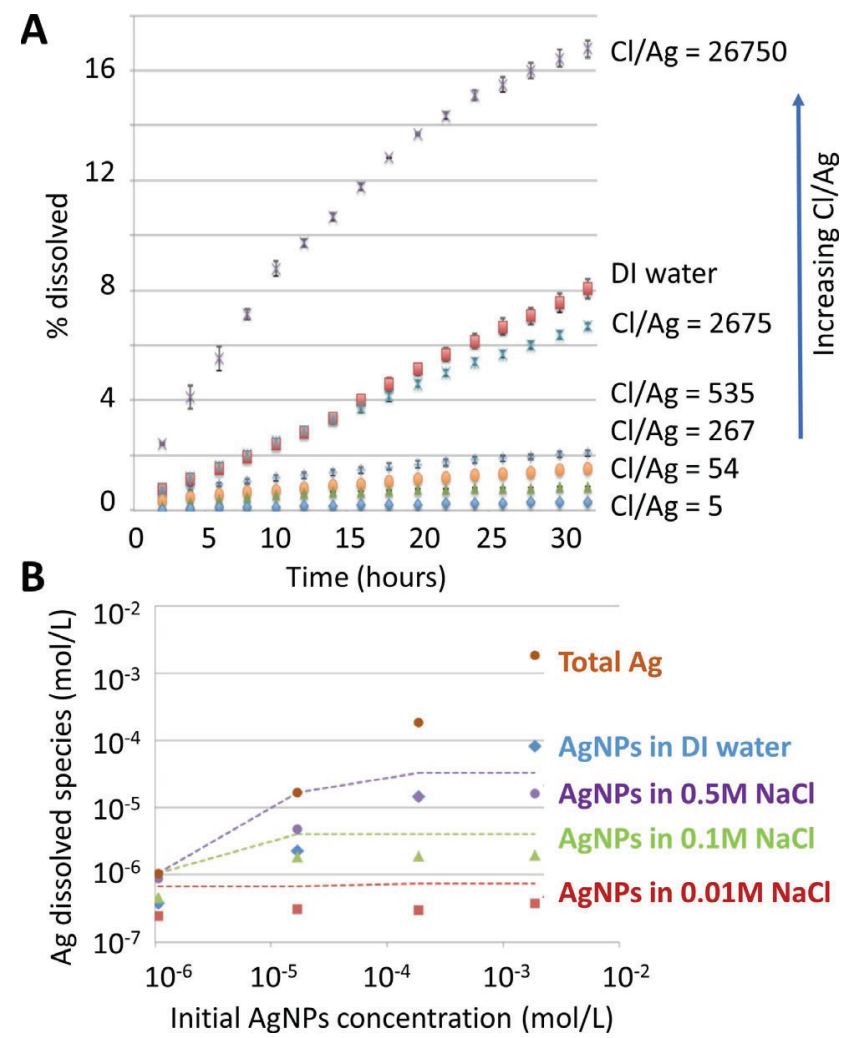

Figure 6. $\mathrm{Ag}^{+}$ion release from $33 \mathrm{~nm} \mathrm{AgNPs}$ in presence of different amounts of chloride: (A) within the first $36 \mathrm{~h}$ by dialysis (B) by ultrafiltration after 12 days ageing. The $\mathrm{Cl} / \mathrm{Ag}$ ratios for $\mathrm{A}$ are realized by combining four different AgNP concentrations with three chloride concentrations $(0.5,0.1$ and $0.01 \mathrm{M}$ ). Adapted with permission from ref. [113]. Copyright 2013, American Chemical Society. 
containing proteins, ${ }^{[116]}$ leading to entities like $\mathrm{Ag}-\mathrm{GSH}, \mathrm{Ag}_{2^{-}}$ GSH or high molecular weight silver GSH coordination polymers. Despite the high binding constants, $\mathrm{Ag}^{+}$was shown to be exchangeable between different thiol ligands as well as inorganic sulfur binding sites, ${ }^{[117]}$ thus toxicity is not entirely suppressed by $\mathrm{Ag}-\mathrm{S}$ binding. ${ }^{[114]}$ Moreover, it was observed that AgNPs did not convert completely into $\mathrm{Ag}_{2} \mathrm{~S}$ even in huge excess of $S^{2-} \cdot{ }^{[115]}$ The formation of a proposed $\mathrm{Ag}_{2} \mathrm{~S}$ layer on AgNPs was confirmed by Liu et al. in an $\mathrm{Ag}^{+}$release experiment with sulfide addition using Ag foils. ${ }^{[61 b]}$ As a consequence, the silver release was completely blocked for $\mathrm{Na}_{2} \mathrm{~S}$ or thiol addition, while citrate addition only slowed it down (the more citrate was added, the less free $\mathrm{Ag}^{+}$was detected) compared to the untreated AgNPs (Figure 7). In the simultaneous presence of biological reductants and sulfur-containing biomolecules, the release trends followed the known binding constants of these substances. In the presence of ligands with multiple thiol groups, the dissolution of AgNPs occurs faster the more thiol groups are present, whereby pre-orientation of these thiol groups for chelation even enhances this effect. ${ }^{[118]}$ These experiments show that surface functionalizing ligands like macromolecular coatings (dextran, starch, polyacryl amide, etc.) and biological relevant molecules may reduce $\mathrm{Ag}^{+}$release by restricting the access to the Ag surface. ${ }^{[68]}$ For citrate, the authors suggest that the citrate molecules blocked the sites for chemisorption of oxygen and additionally that $\mathrm{Ag}^{+}$was reversibly bound to one of the free carboxylic acid groups of a citrate molecule at the AgNP surface. The possibility of $\mathrm{Ag}^{+}$reduction to $\mathrm{Ag}$ by citrate was discussed to explain the slower rate and lower dissolution degree of citrate capped AgNPs compared to PVP or gum arabic capped AgNPs of the same size. ${ }^{[45,142]}$ Complexation of free $\mathrm{Ag}^{+}$by excess citrate and subsequent adsorption on AgNPs, leading to a lower toxicity, was also proposed. ${ }^{[119]}$

Nanoparticles exposed to real body fluids or full biological media get immediately covered by a so-called protein corona. For a variety of other nanomaterials like silica, polystyrene, or $\mathrm{Au}$, this phenomenon was studied in detail. ${ }^{[120]}$ The composi- tion of the protein corona depends on the initial surface coating, the surface charge and particle size and was characterized for instance for a group of four different Ag colloids (110 nmPVP, $110 \mathrm{~nm}$-citrate, $20 \mathrm{~nm}$-PVP and $20 \mathrm{~nm}$-citrate) in FBS-supplemented cell culture medium (DMEM). ${ }^{[121]}$ Levak et al. found reduced release rates for $\mathrm{Ag}$ particles in presence of albumin in seawater with high salinity, thus suggesting a very high persistence of AgNPs if stabilized by proteins, ${ }^{[122]}$ which also lead to a decrease of the toxicity as removal of serum proteins significantly increases their impact. ${ }^{[123]}$ Citrate-capped AgNPs used in the same study did not show this effect. Zook et al. found average dissolution rates of $5 \% \mathrm{~h}^{-1}$ for AgNPs in DMEM supplemented with BSA regardless of the used coating and only minimal dissolution in moderately hard, reconstituted water supplemented with humic acid, ${ }^{126}$ a result confirmed by Ivask et al. ${ }^{[80 b]}$ While DMEM had only a weak effect on better dissolution, Liu et al. showed that BSA increased the dissolution of AgNPs in artificial extracellular fluid as mimic of wound exudate (PECF, see Figure 8). ${ }^{[16]}$ Their study investigated the pathway from oral intake of AgNPs to the development of argy$\mathrm{ria}^{[124]}$ the irreversible blueish-grey coloration of light affected skin caused by overexposure to silver. Increased dissolution of AgNPs in gastric fluid enables the uptake of $\mathrm{Ag}^{+}$into the systemic circulation and bloodstream, resulting in their complexation by proteins with human serum albumin (HSA) as a likely transporter. In near skin regions, $\mathrm{Ag}^{+}$-biocomplexes could be easily reduced to AgNPs as Liu et al. showed in their photoreduction experiments. These AgNPs can be transformed to $\mathrm{Ag}_{2} \mathrm{~S}$ and $\mathrm{Ag}_{2} \mathrm{Se}$ under biologically relevant conditions, thus possibly explaining the formation of $\mathrm{Ag} / \mathrm{S} / \mathrm{Se}$ particles found in argyria skin.

Stebounova et al. investigated the fate of AgNPs in artificial interstitial fluid $(\mathrm{pH} \mathrm{7.4)}$ and artificial lysosomal fluid $(\mathrm{pH} 4.5-5)$ as mimics for lung exposure. ${ }^{[125]}$ They found only negligible dissolution (1\%), but aggregation and sedimentation independent of the used particle coating and the medium, as attributed to the high ionic strength of such media. Jiang et al. supposed
A

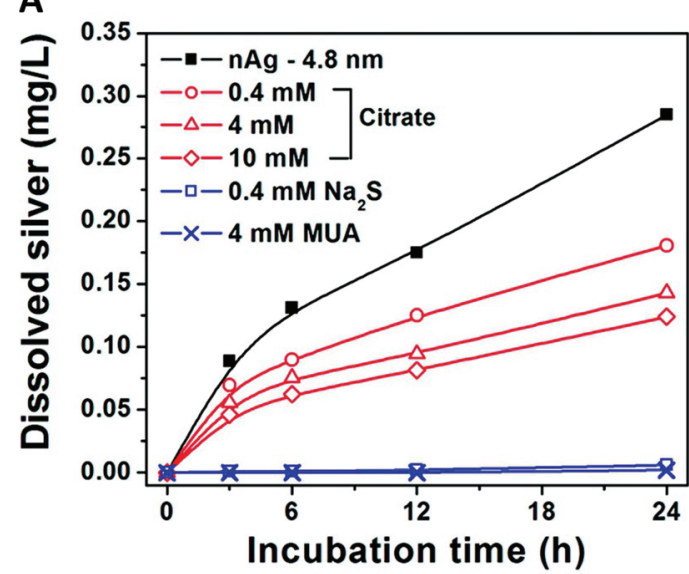

B

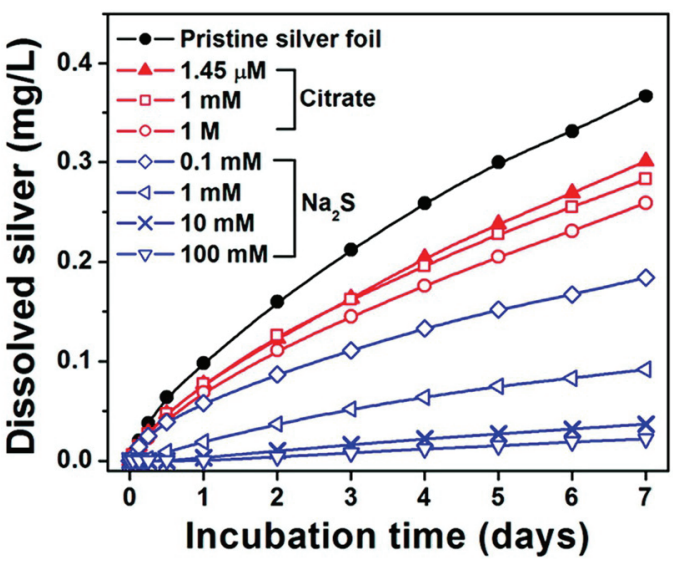

Figure 7. Dissolution from (A) $4.8 \mathrm{~nm}$ AgNPs and (B) Ag foil under addition of different surface coating ligands in varying concentrations for $24 \mathrm{~h}$, at RT, in $\mathrm{pH}=5.6$ acetate buffer. Reprinted with permission from ref. [61b]. Copyright 2010, American Chemical Society. 


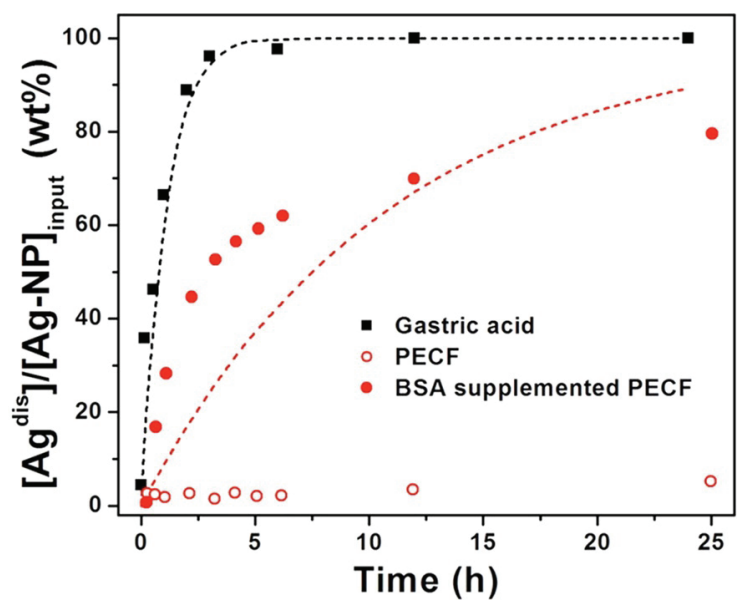

Figure 8. Increased $\mathrm{Ag}^{+}$ion release from $5 \mathrm{~nm}$ citrate capped AgNPs in gastric fluid ( $\mathrm{pH}$ 1.12) and BSA-supplemented pseudoextracellular fluid $\left(\mathrm{PECF}+20 \mathrm{~g} \mathrm{~L}^{-1} \mathrm{BSA}\right)$, compared to pure PECF $(\mathrm{pH} 7.52,117 \mathrm{mM} \mathrm{NaCl}$, $30 \mathrm{~mm} \mathrm{KCl}, 300 \mathrm{~mm} \mathrm{NaHCO}, 26 \mathrm{~mm} \mathrm{KH}_{2} \mathrm{PO}_{4}$ ). Reprinted with permission from ref. [116]. Copyright 2012, American Chemical Society.

the same reasons for their moderate release determined in cell culture medium at $\mathrm{pH} 4.5(7.5 \%)$ and $7.0(5 \%)$ after $24 \mathrm{~h} .{ }^{[126]}$

Severe aggregation from AgNPs of $1.9 \mathrm{~nm}$ to $200 \mathrm{~nm}$ (DLS), leading to lower $\mathrm{Ag}^{+}$release, was observed in natural seawater, which was attributed mainly to the higher $\mathrm{pH}^{\left[{ }^{[06]}\right.}$ Addition of natural organic matter (NOM, for example, Suwannee River humic or fulvic acid) lowered the amount of release in a dose dependent way. ${ }^{[106]}$ Yet, other studies reported both increased dissolution and stabilization of AgNPs through interactions with organic matter. ${ }^{[46]}$

In conclusion, precipitation as $\mathrm{AgCl}$, coordination to proteins, aggregation, sedimentation, cellular uptake, and/or photoreduction (and more) may compete with each other and impede thus the unveiling of toxicity mechanisms. Liu et al. summarized their findings in the schemes presented in Figure 9 showing the various possibilities to control $\mathrm{Ag}^{+}$release rates through surface modifications.

\subsubsection{Determination of the intracellular AgNP dissolution}

Although the experiments described above draw a comprehensive picture of the AgNP dissolution under various conditions, the results are not sufficient to provide satisfactory explanations for the observed biological effects. For this reason, current research studies release experiments in the presence of living cells, prokaryotes and eukaryotes, and intracellular $\mathrm{Ag}$ speciation.

Bondarenko et al. tried to elucidate the antimicrobial mechanism by investigation of the dissolution of three different types of AgNPs ["uncoated" (30-100 nm), casein coated (5$30 \mathrm{~nm})$, and PVP coated $(8-11 \mathrm{~nm})]$ in bacterial growth medium with (biotic) or without cells (abiotic) (Figure 10A). ${ }^{[63 a]}$ They found the same release trends for all conditions and all methods with the $\mathrm{Ag}^{+}$concentrations decreasing in the following order: PVP-capped AgNPs > casein capped AgNPs $>$ "uncoated" AgNPs. All released fractions were slightly higher under biotic conditions compared to abiotic ones with the

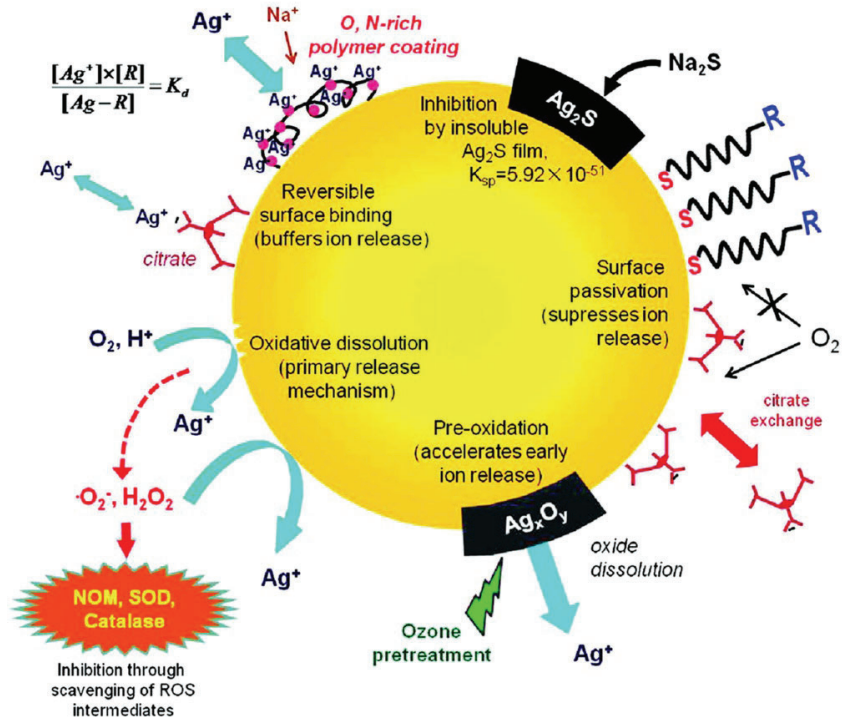

Figure 9. Schematic summary of the interactions influencing the $\mathrm{Ag}^{+}$release at nanosilver surfaces. Reprinted with permission from ref. [61b]. Copyright 2010, American Chemical Society.

most dramatic difference for the intracellular $\mathrm{Ag}^{+}$concentration determined by a bioluminescent $\mathrm{Ag}^{+}$sensitive E. coli strain (Figure 10B). Interestingly, the fraction of intracellular $\mathrm{Ag}^{+}$under biotic conditions was higher than the extracellular $\mathrm{Ag}^{+}$concentrations under both, biotic and abiotic conditions. Thus, the usual determination of the released fraction measured in cell culture medium may underestimate the bioavailable $\mathrm{Ag}^{+}$concentration. The observation that the intracellular concentration of the E. coli biosensor strain is lower than the external one if the bacterial cells are only exposed to $\mathrm{Ag}^{+}$corroborates the huge influence of cell-AgNP contact for high intracellular $\mathrm{Ag}^{+}$concentrations. At the same time, the presence of the bacterial cells does not seem to greatly increase the extracellular dissolution.

In contrast, Joshi et al. did not observe the increase of the intracellular $\mathrm{Ag}^{+}$concentration upon exposure to AgNPs using a bioluminescent $E$. coli strain, as bacteria died before $\mathrm{Ag}^{+}$ could be measured. ${ }^{[127]}$ Hsueh et al. found that released $\mathrm{Ag}^{+}$ adhered to or was internalized by the cells mainly in form of $\mathrm{Ag}_{2} \mathrm{O}$, and surprisingly did not detect any sulfur in the samples. $^{[128]}$

De Matteis et al. showed an increased release compared to the cell culture medium only for the intracellular release kinetics of AgNPs in HeLa and A549 cells. ${ }^{[129]} \mathrm{Ag}^{+}$diffused through the whole cell (cytoplasm, organelles, nucleus) and increased significantly over time. An influence of the used fluorescent probe on the kinetics could however not be excluded. Jiang et al. have studied the fate of intracellular AgNPs in $\mathrm{CHO}-\mathrm{K} 1$ cells. ${ }^{[26]}$ They found a dissolved fraction of $55 \%$ for the uptaken $\mathrm{Ag}$ after $1 \mathrm{~h}$ incubation, respectively $>80 \%$ after $24 \mathrm{~h}$. In parallel, the amount of $\mathrm{Ag}^{0}$ in the cell culture medium decreased from $80 \%$ to $40 \%$ after $24 \mathrm{~h}$, while the remaining $20 \%$, respectively $60 \%$ were found as Ag-S species. 
A 1 Biotic dissolution

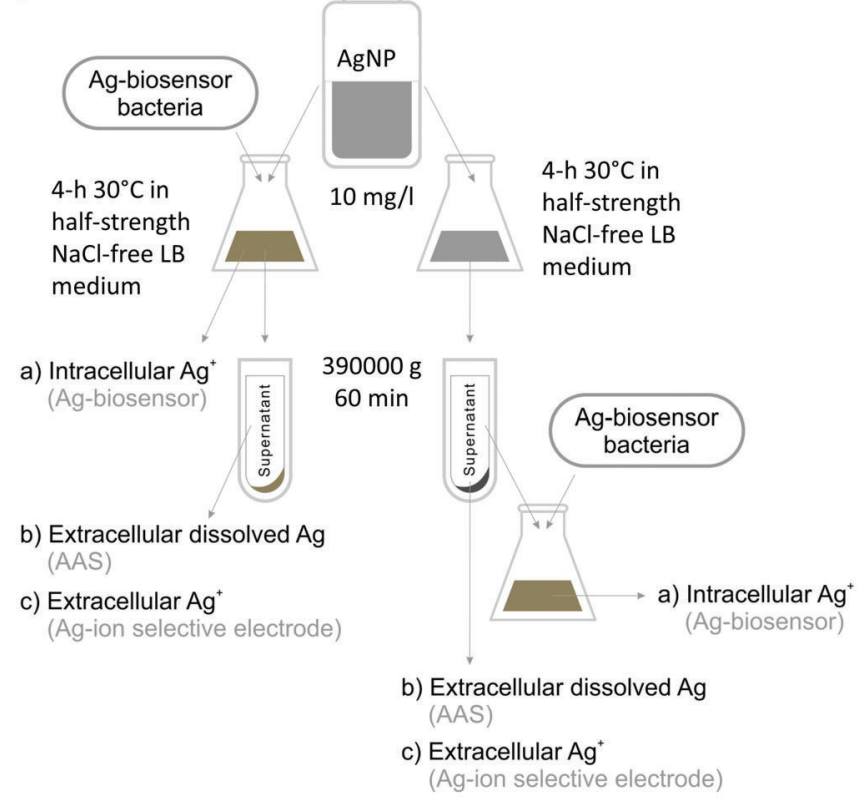

B

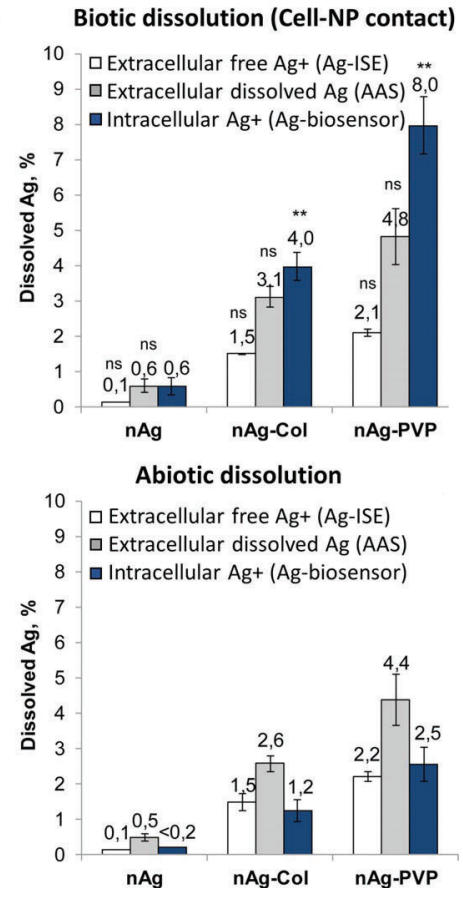

Figure 10. AgNP dissolution in bacterial growth medium under biotic and abiotic conditions by AAS, ISE and bioluminescent E. coli: (A) schematic explanation of the experiment and (B) resulting dissolved fractions. Modified from ref. [63a] licensed under CC BY 4.0.

Veronesi et al. found the released fraction in murine macrophages to increase from $9 \%$ to $39 \%$ between 6 to $24 \mathrm{~h}$ using a dose of $5 \mu \mathrm{g} \mathrm{mL}^{-1}$. 130] Using instead a chronic dose of $1.25 \mu \mathrm{g} \mathrm{mL}^{-1}$ over 4 days, they found a higher released fraction of $73 \%$, but no increased cytotoxicity despite the uptake of almost the double amount of silver. ${ }^{[130 b]}$ Human hepatocytes showed a faster dissolution of citrate capped AgNPs compared to PVP capped ones, with transformation into Ag-S species. ${ }^{[130 a]}$ Depending on the cell type, the $\mathrm{Ag}-\mathrm{S}$ bond lengths matched either to a digonal coordination mode $\mathrm{AgS}_{2}$ that would correspond to the formation of GSH complexes (murine macrophages $)^{[130 b]}$ or to a trigonal coordination mode $\mathrm{AgS}_{3}$ that was found in metallothioneins (human hepatocytes), ${ }_{1}^{[130 a]}$ as confirmed by upregulation of metallothioneins in hepatocytes.

\subsection{Methodologies for silver detection}

The effect of $\mathrm{Ag}^{+}$release on the particle size is usually negligible small: A released fraction of $10 \%$ means only $3.45 \%$ reduction of the diameter, for example, corresponding to $19.3 \mathrm{~nm}$ for an initially $20 \mathrm{~nm}$ AgNP (Table 2). Hence, particle size measurements are not sufficient to prove the stability of a certain type of NPs.

AgNPs are usually separated from the ionic $\mathrm{Ag}^{+}$by (ultra)centrifugation, ultra/nanofiltration or dialysis. The released $\mathrm{Ag}^{+}$can then be quantified by inductively coupled plasma mass spectrometry (ICP-MS), inductively coupled plasma optical emission spectrometry (ICP-OES), or graphite furnace atomic absorption spectrometry (AAS). Each separation method faces some disadvantages. Firstly, $\mathrm{Ag}^{+}$ions can stick to the membranes of ultrafiltration devices or dialysis tubing and centrifugation is not always complete, especially for very small NPs. Addition of EDTA before centrifuging helps to separate the adsorbed $\mathrm{Ag}^{+}$on the AgNP surface. ${ }^{[131]}$ When EDTA was added $10 \mathrm{~min}$ prior to ultracentrifugation, the determined released fraction doubled (from $5 \%$ to $10 \%$ ) without changing further over time. ${ }^{[132]}$ Secondly, the separation method could influence the release kinetics if it is faster than the separation. Kittler et al. described in detail their experimental conditions for dialysis and performed the necessary control experiments excluding irreversible interactions of the released $\mathrm{Ag}^{+}$with the dialysis membrane (Spectra/Por Biotech, cellulose ester; MWCO 100000). ${ }^{[45]}$ While ionic silver could be recovered completely in

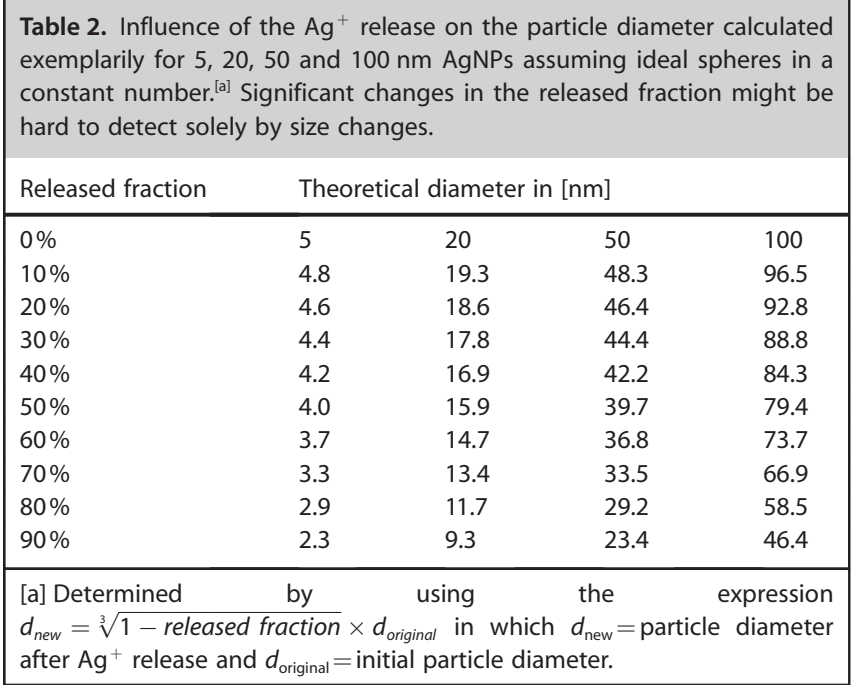


the dialysate within a few hours, the AgNPs did not leak into the dialysate. Complete renewal of the dialysate at each time point leads to new burst releases ${ }^{[109]}$ and maximizes the driving force for release. ${ }^{[13]}$ Third, AAS or AES are sensitive to matrix effects, for example, the presence of chloride, ${ }^{[133]}$ complicating experiments in biological or environmental fluids.

Other methods for determination of the $\mathrm{Ag}^{+}$concentration are ion-selective electrodes (ISE) and ion chromatography. They measure only the amount of "free" $\mathrm{Ag}^{+}$ions and ignore all precipitated or complexed forms, ${ }^{[75 b]}$ while Bondarenko et al. reported twice as high released fractions measured with AAS compared to ISE. ${ }^{[63 a]}$ Thus, values for "dissolved" Ag need specification for the used method. With ISE reporting "free" $\mathrm{Ag}^{+}$and AAS/OES or MS reporting the fraction of free $\mathrm{Ag}^{+}$ ions together with low molecular weight complexes (e.g. citrate, or $\mathrm{AgCl}_{x}^{(x-1)-}$ ), they are not able to record $\mathrm{Ag}^{+}$trapped in high molecular weight complexes for example, with proteins, humic acid or insoluble salts. One option is thus to measure the remaining AgNP-fraction in a release experiment by correlation to the area under the UV/Vis band of the $\mathrm{LSPR}{ }^{[104]}$ allowing to differentiate reduced $\mathrm{Ag}$ from any $\mathrm{Ag}$ in oxidized forms (complexes, precipitates, ionic). Linearity of the Beer-Lambertlaw for the used NP system needs to be ensured, and the contribution of scattering from for example, $\mathrm{AgCl}$ particles to be taken into account. DLS experiments should backup the assumption that the used NPs do not change their agglomeration state within the dissolution experiment.

For differentiation between $\mathrm{Ag}^{+}$and AgNPs in more complex environments such cell lysate, a Triton X-114-based cloud point extraction (CPE) method has been developed by the group of Yin. ${ }^{[134]} \mathrm{Na}_{2} \mathrm{~S}_{2} \mathrm{O}_{3}$ addition, $\mathrm{pH}$ adjustment to 3.5, short incubation and slight centrifugation helped to separate the Triton $\mathrm{X}$ rich phase with the AgNPs from the supernatant aqueous phase containing the $\mathrm{Ag}^{+}$.

Another method uses a rosamine derivative with a macrocyclic ligand as a fluorescent probe for intracellular $\mathrm{Ag}^{+}$quantification. ${ }^{[135]}$ A selective fluorescence enhancement upon binding with $\mathrm{Ag}^{+}$with a detection limit of $1 \times 10^{-7} \mathrm{M} . \mathrm{Ag}^{+}$uptake was shown in MCF-7 cells exposed to the probe and afterwards to $\mathrm{Ag}^{+}$. For fluorescence detection of intracellular $\mathrm{Ag}^{+}$in prokaryotic cells, genetically modified bioreporter E. coli strains have been developed that exhibit bioluminescence selectively in presence of $\mathrm{Ag}^{+}{ }^{[136]}$ They give a linear response to intracellular $\mathrm{Ag}^{+}$in the sublethal concentration range. ${ }^{[63 a, 127]}$

Wildt et al. proposed a microscopy analysis for detection of intracellular release by visualization of AgNP uptake and dissolution by quantification of darker areas in live cell time lapse microscopy images (nanoparticle associated cytotoxicity microscopy analysis, NACMA). ${ }^{[63 c]}$ The advantage of this technique lies in the direct time correlation to the simultaneously determined cytotoxic effects, but conclusions remain difficult as agglomerates or particles below $100 \mathrm{~nm}$ might not be detected.

Amongst others, Veronesi et al. used X-ray absorption spectroscopy (EXAFS and XANES) for the speciation of silver. ${ }^{[130 b]}$ Linear combination analysis of the XANES data from reference compounds (e.g. $\mathrm{AgNO}_{3}, \mathrm{AgCl}, \mathrm{AgGSH}$ ) and the sample gives access to the released fraction, but also to the binding part- ners of released $\mathrm{Ag}^{+}$. $\mathrm{Ab}$ initio modeling of the EXAFS part even allowed the determination of the $\mathrm{Ag}-\mathrm{S}$ coordination mode and bond lengths. ${ }^{[130 b]}$

Altogether these methods enable the detailed analysis of the intracellular fate of $\mathrm{Ag}$ for prokaryotic as well as eukaryotic cells, and thus further elucidation of the biological mechanism of action.

\subsection{Biological impact of silver}

In biological experiments, the effect of $\mathrm{a} \mathrm{Ag}^{0}$ dose is often compared to the equivalent amount of a silver salt as control. $\mathrm{Ag}^{+}$ions then usually show a higher activity at the same concentrations, while the effects are similar. For instance, Foldbjerg et al. determined the $\mathrm{EC}_{50}$ for the lung cancer cells $\mathrm{A} 549$ to be two times lower for $\mathrm{Ag}^{+}$than for the studied AgNPs, ${ }^{[137]}$ an effect confirmed by Ivask et al. for a broad range of organisms, from algae to bacteria or mammalian cells. ${ }^{[80 b]}$ Kittler et al. could correlate the increased toxicity of AgNPs towards human mesenchymal stem cells with storage time of the samples to the progression of oxidative dissolution leading. ${ }^{[45]}$ Also, $\mathrm{AgNO}_{3}$ was found three times more toxic than AgNPs with respect to the total $\mathrm{Ag}$ amount. Bouwmeester et al. found that concentrations up to $50 \mu \mathrm{g} \mathrm{mL}^{-1}$ of the AgNPs had no effect on cell viability, whereas $2.5 \mu \mathrm{g} \mathrm{mL}^{-1} \mathrm{Ag}^{+}$were already toxic. ${ }^{[138]}$ The gene expression response and translocation of silver was the same for AgNPs and $\mathrm{Ag}^{+}$ions after $4 \mathrm{~h}$. Upon longer exposure, Foldbjerg et al. found indications for more complex affection of A549 cells from AgNPs compared to $\mathrm{Ag}^{+}$ when looking at their gene expression. ${ }^{[139]}$ This is in line with other studies, which found biological effects that could not be explained with only the released $\mathrm{Ag}^{+}$fraction. Beer et al. for instance compared the toxicity of nanosilver suspensions before and after removal of the AgNPs by centrifugation. ${ }^{[140]}$ For suspensions with a $\mathrm{Ag}^{+}$fraction of $>2.6 \%$, the toxicity of the supernatant was the same than of the original AgNP suspension, whereas below that, the presence of the AgNPs lead to additional toxicity. Suresh et al. found $\mathrm{EC}_{50}$ values for four types of AgNPs to be lower or in the same range than for $\mathrm{AgNO}_{3}{ }^{[141]}$ The differences in toxicity for different AgNPs were attributed to their surface coatings, altering the dissolution in vivo. Jiang et al. found a clear time dependent correlation of the $\mathrm{Ag}^{+}$ amounts and the toxic effects, ${ }^{[126]}$ supporting the Trojan horse mechanism: first AgNPs uptake, then dissolution to $\mathrm{Ag}^{+}$, and then interaction with proteins and amino acids. ${ }^{[126]}$ Increased ROS production has also always been one of the toxicity mechanisms attributed to the presence of Ag particles, ${ }^{[119,142]}$ yet its mere detection or quantification leaves the question open if particles or $\mathrm{Ag}^{+}$are the underlying cause. Guo et al. reported the same ROS levels for equivalent doses of $\mathrm{Ag}^{+}$and AgNPs $\left(1 \mu \mathrm{gL}^{-1}\right)$, but significantly higher levels of cytotoxicity for the ions suggesting additional, different toxicity mechanisms (Figure 11$).{ }^{[143]}$ A pre-incubation with silver-binding $\mathrm{N}$-acetylcysteine (NAC) or vitamin C as antioxidants were observed to reverse ROS generation for AgNPs and $\mathrm{Ag}^{+}$, while only NAC could also prevent the loss of mitochondrial membrane potential, DNA damage and apoptosis. Jiang et al. confirmed this 

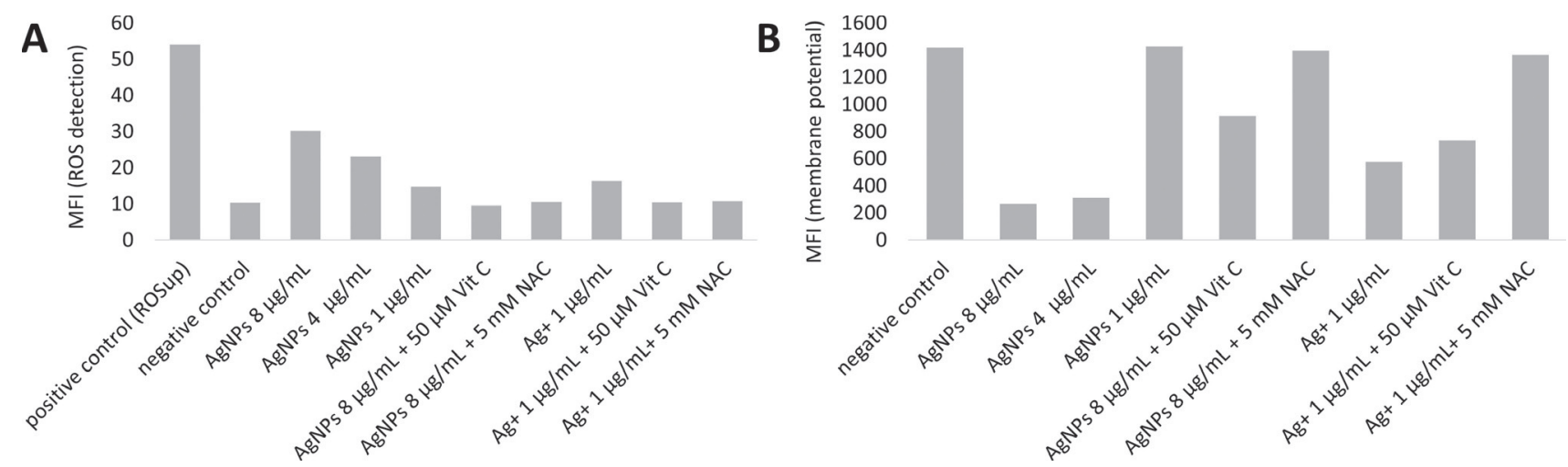

Figure 11. Generation of ROS (A) and influence on the mitochondrial membrane potential of SHI-1 cells (B) upon exposure to $11 \mathrm{~nm}$ AgNPs or Ag ${ }^{+}$with or without addition of vitamin C or NAC. Generated with data from ref. [143].

positive effect of NAC on cell viability in their study, but found it to be more pronounced for $\mathrm{Ag}^{+}$than AgNPs. ${ }^{[126]}$

De Matteis et al. confirmed the above-mentioned Trojan horse mechanism for the toxicity in mammalian cells, ${ }^{[129]}$ and showed the suppression of Ag induced ROS by addition of 2,3dithiopropanol (BAL) as another strong $\mathrm{Ag}^{+}$chelator. However, BAL could also act as antioxidant with ROS being induced by AgNPs.

Ag uptake in the form of AgNPs and their subsequent intracellular dissolution was revealed clearly by XANES/EXAFS studies and synchrotron based nano-beam X-ray fluorescence (XRF) microscopy, which confirmed the binding of the released $\mathrm{Ag}^{+}$ to $S$ in digonal or trigonal coordination modes as described before. ${ }^{[130]}$ In combination with TEM analysis, the observed hotspots with high Ag intensity were identified as intracellular vesicles containing AgNPs, as confirmed by Herault et al., ${ }^{[144]}$ while no AgNPs were found in the cytosol. The experiments also showed that the cells could handle much higher amounts of $\mathrm{Ag}^{+}$dissolved from AgNPs compared to the lethal levels if administered in ionic form. With all the above-mentioned advanced studies in mind, the Trojan horse mechanism seems to offer the best explanations for the toxic effects of AgNPs in mammalian cells, supporting on one hand the strict correlation of the toxicity to $\mathrm{Ag}^{+}$as active species, but also offering a reasonable explanation for correlations of particle properties with biological effects.

Ecotoxicity is generally attributed to the amount of released $\mathrm{Ag}^{+} .{ }^{[145]}$ Experiments of Lee et al. with Daphnia magna for citrate stabilized and non-coated AgNPs showed significant lower $\mathrm{EC}_{50}$ for the uncoated ones. ${ }^{[75 \mathrm{~b}]}$ The dissolved fractions in both experiments showed $\mathrm{Ag}^{+}$concentrations in the same range that corresponded as well to the $\mathrm{EC}_{50}$ determined for $\mathrm{AgNO}_{3}$ $\left(0.5 \mu \mathrm{L} \mathrm{L}^{-1} \mathrm{Ag}\right)$. Yang et al. reported a linear correlation between dissolution and toxicity towards Caenorhabditis elegans. ${ }^{[119]}$ The toxicity of the AgNPs was sensitive to ionic strength and chloride concentration, and reported to never exceed the value of the same amount of $\mathrm{Ag}^{+} .{ }^{[119]}$ In the studies with the algae Chlamydomonas reinhardtii, $\mathrm{Ag}^{+}$was 18 times more toxic than AgNPs based on the nominal Ag concentration, but the dissolved fraction of AgNPs $(<1 \%)$ was not enough to explain fully their toxicity. ${ }^{[146]}$ Addition of cysteine as strong $\mathrm{Ag}^{+}$ligand eliminated the inhibition of the algae for both species. The generally lower toxicity in the presence of complexing ligands or precipitating anions is a hint at $\mathrm{Ag}^{+}$as active species. Indeed, $\mathrm{Cl}^{-}$reduced the toxicity towards fish, ${ }^{[147]}$ and thiols also towards bacteria. ${ }^{[61 b, 148]}$ Xiu et al. could even attribute the complete toxicity against bacteria to the $\mathrm{Ag}^{+}$release by testing AgNPs under aerobic and anaerobic conditions (Figure 12). ${ }^{[73]}$ E. coli then demonstrated equal susceptibility to $\mathrm{Ag}^{+}$under either condition, while AgNPs were only antimicrobially active under aerobic conditions. They thus precluded particle-specific antibacterial mechanisms.

In contrast, Jin et al. found that in artificial freshwater, the effective $\mathrm{Ag}^{+}$concentration was the same regardless if NP or $\mathrm{Ag}^{+}$was added, yet the $\mathrm{IC}_{50}$ of silver nitrate was magnitudes lower than for AgNPs, suggesting a different bioavailability depending on the speciation resulting from either AgNP or ion administration. ${ }^{[149]}$ Ivask et al. observed that citrate capped AgNPs had a size dependent toxicity towards various organisms (crustaceans, algae, bacteria, mammalian cells). ${ }^{[80 \mathrm{~b}]}$ Normalizing the $\mathrm{EC}_{50}$ values for the different organisms to the dissolved fraction found at the toxicological endpoint in the respective medium, the values became always similar to the $\mathrm{EC}_{50}$ determined for $\mathrm{Ag}^{+}$. Only the $\mathrm{Ag}$ colloid with the smallest particle size $(10 \mathrm{~nm})$ showed a significantly increased toxicity that could not be attributed to the released fraction. Normalization to the bioavailable fraction of $\mathrm{Ag}$, which was determined by exposure of sublethal $\mathrm{AgNP}$ concentrations to a $\mathrm{Ag}^{+}$induced bioluminescent E. coli strain, explained the higher toxicity of the $10 \mathrm{~nm}$ AgNPs, at least for E. coli. This kind of experiment opens up the questions if the bioavailability of $\mathrm{Ag}^{+}$in bacteria results from dissolution of the AgNPs in the growth medium, or from intracellular dissolution, or from dissolution in close proximity to the cells.

In experiments with $x \mathrm{Ag} / \mathrm{SiO}_{2}$ nanocomposites ( $x=\mathrm{wt} \% \mathrm{Ag}$ ), a correlation of the antimicrobial activity with the release trends, combined with an exceptional behavior for one of the examined materials was observed. ${ }^{[80 \mathrm{a}]}$ While the antimicrobial activity for the $\mathrm{Ag}^{+}$containing supernatants was equal to the one of complete suspensions for samples of $1 \mathrm{mg}(\mathrm{Ag}) \mathrm{L}^{-1}$ (Figure $13 \mathrm{~B}$, part I), materials with higher $\mathrm{Ag}$ wt $\%$ inhibited the bacterial growth to a larger extend than the supernatant alone 


\section{A

\begin{tabular}{ll}
\hline Anaerobic exposure & Aerobic exposure \\
\hline$\square 5 \mathrm{~nm}$ & $\Delta$ Not aerated \\
\hline$\bullet 11 \mathrm{~nm}$ & $\nabla$ Aerated for $48-\mathrm{h}$ \\
\hline
\end{tabular}

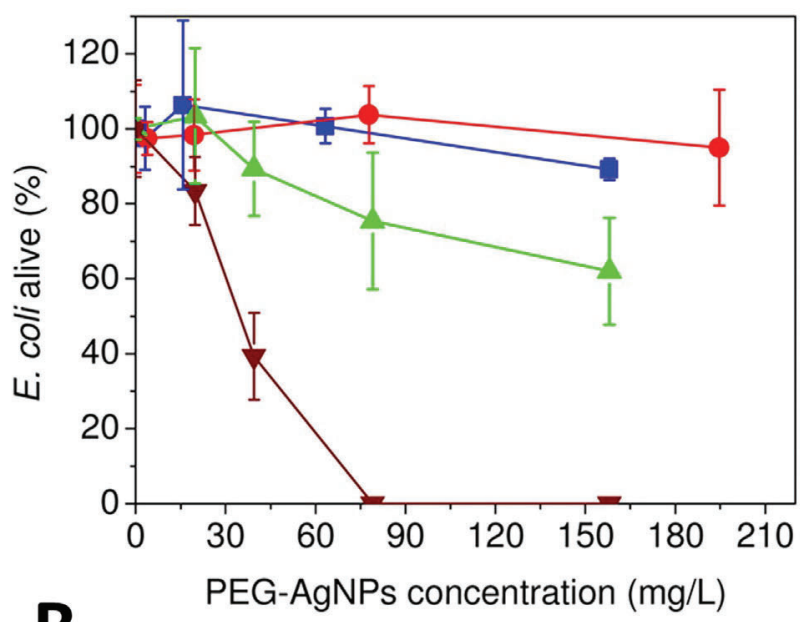

B

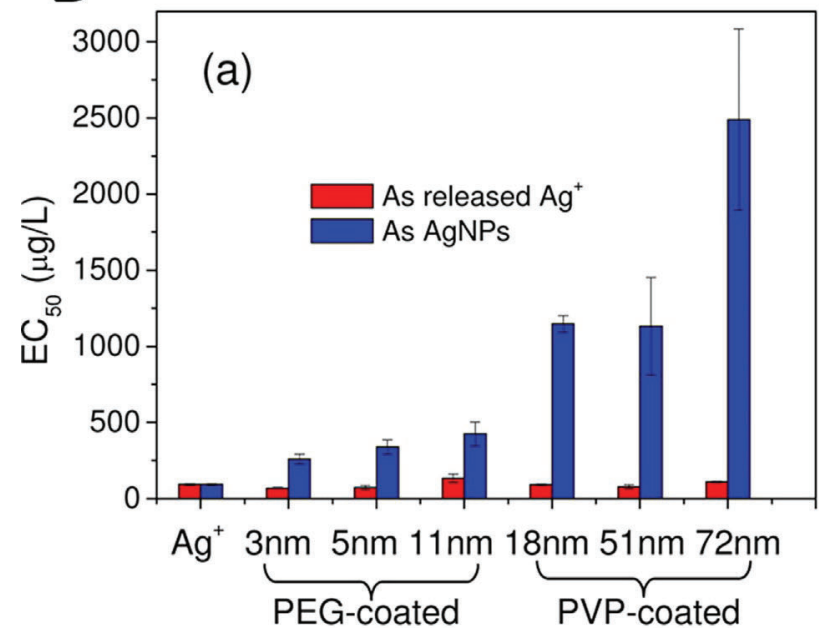

Figure 12. Antibacterial efficiency of AgNPs in dependence of the oxygen availability: (A) No effect under anaerobic synthesis and growth conditions, dose dependent bactericidal effect for aged AgNPs and slight antibacterial effect for anaerobic synthesis but aerobic growth conditions; (B) Huge variation of $\mathrm{EC}_{50}$ for different AgNPs against $E$. coli if expressed as total $\mathrm{Ag}$ amount vanishing if expressed as released fraction. Reprinted with permission from ref. [73]. Copyright 2012, American Chemical Society.

(Figure 13B, part II). This indicates that the antimicrobial activity of the bigger AgNPs with low released fraction is governed by both, the $\mathrm{Ag}^{+}$release and the presence of particles. Finally, Bondarenko et al. hypothesized that AgNPs might not be toxic to the cells per se, but that they serve as carriers to bring the toxic $\mathrm{Ag}^{+}$in close proximity to the bacterial cells ${ }^{[63 a]}$ as sometimes the determined released fraction is not enough to explain the toxicity if compared to the toxic concentrations of silver nitrate. ${ }^{[80 a, 150]}$ The dose-response curves measured for six different bacterial strains were similar for silver nitrate $\left(E C_{50}\right.$ 0.3-1.2 $\mathrm{mg} \mathrm{L}^{-1}$ ), but differed significantly for the differently synthesized AgNPs ( $E C_{50} 0.35$ to $46.1 \mathrm{mg} \mathrm{L}^{-1}$ ). As the dissolution
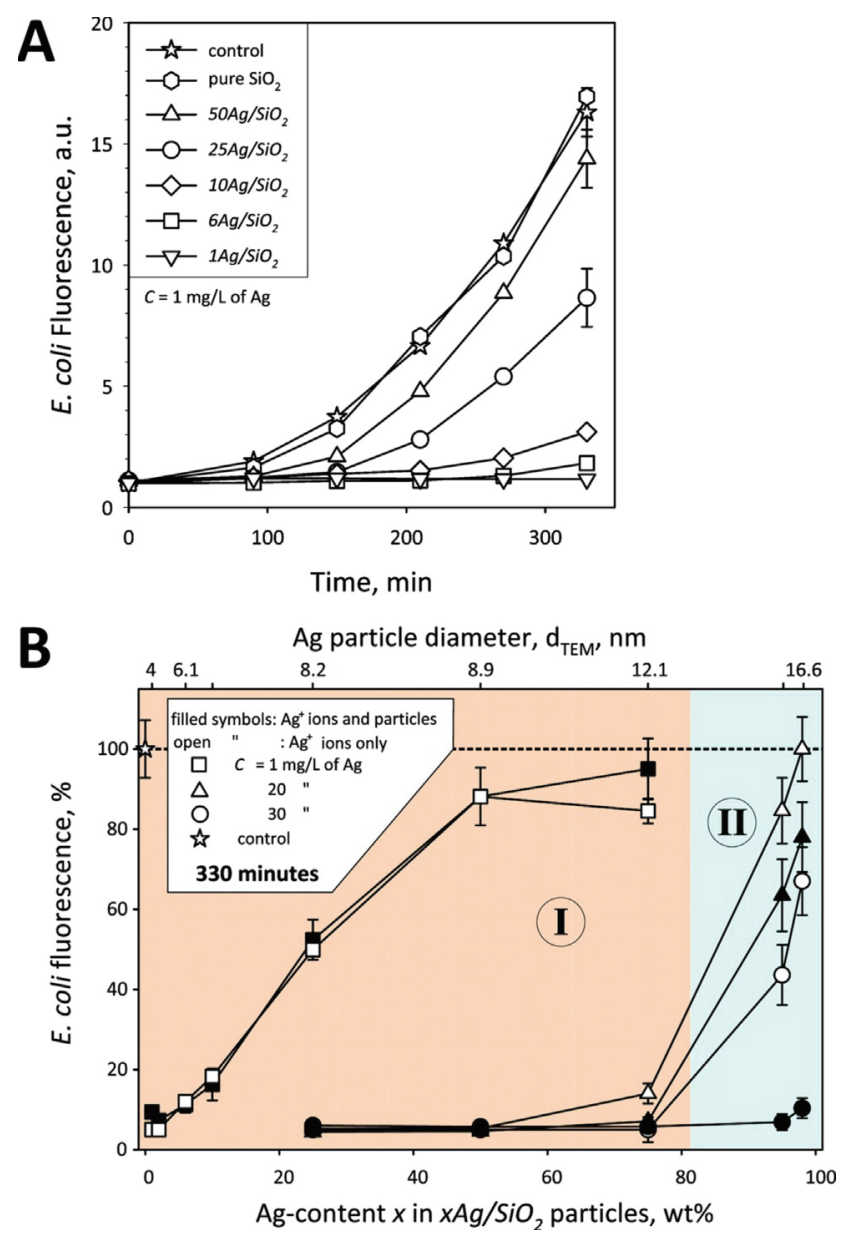

Figure 13. (A) E. coli growth (fluorescence) in presence of $1 \mathrm{mg}(\mathrm{Ag}) \mathrm{L}^{-1} x \mathrm{Ag} /$ $\mathrm{SiO}_{2}$ nanocomposites with $x$ as $\mathrm{Ag}$ content in wt \%. The larger the Ag content, the bigger the AgNP size and the lower the released fraction. (B) E. coli growth after 330 min incubation with different concentrations: $1 \mathrm{mg}(\mathrm{Ag}) \mathrm{L}^{-1}$

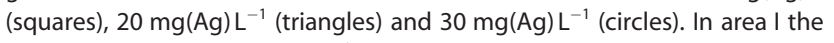
antimicrobial effect of only $\mathrm{Ag}^{+}$containing supernatant is the same than of the complete suspension. In area II removal of the particles lowers the antimicrobial effect. Reprinted with permission from ref. [80a]. Copyright 2010, American Chemical Society.

experiments under biotic and abiotic conditions (Figure 10) suggested that AgNP-cell contact leads to higher intracellular $\mathrm{Ag}^{+}$concentrations, the strain specific AgNP toxicity might thus be governed by a stronger adherence of the AgNPs to the more susceptible strains, for example, P. aeruginosa.

McQuillan et al. suggested that type of mechanism already earlier as "nanoparticle enhanced silver ion stress". ${ }^{[151]}$ They observed a close association of the used AgNPs to the cell membranes and in the cytosol by TEM imaging and could not explain the observed toxicity with the measured $\mathrm{Ag}^{+}$concentration in the growth medium.

Hence, even though AgNPs may show the same bactericidal effect than the amount of $\mathrm{AgNO}_{3}$ equivalent to their released fraction, this does not prove that both act with the same mechanism. ${ }^{[152]}$ The investigation of the intracellular availability of $\mathrm{Ag}^{+}$in bioluminescent . coli $^{[136]}$ gave an excellent correlation with the found antimicrobial activity for five different AgNP types and $\mathrm{AgNO}_{3}$. Table 3 shows how the differences in 


\begin{tabular}{|c|c|c|c|c|c|c|}
\hline & Ag-cit $_{10}$ & Ag-cit 20 & $\mathrm{Ag}^{-\mathrm{cit}_{40}}$ & $\mathrm{Ag}-\mathrm{PVP}_{18}$ & $\mathrm{Ag}-\mathrm{BPEI}_{23}$ & $\mathrm{Ag}-\mathrm{NO}_{3}$ \\
\hline $\mathrm{IC}_{50}, \mathrm{mg}$ of added $\left[\mathrm{Ag} \mathrm{L}^{-1}\right]$ & 6.4 & 15.7 & 40.9 & 5.5 & 2.2 & 2 \\
\hline $\mathrm{IC}_{50}, \mathrm{mg}$ of dissolved $\left[\mathrm{Ag} \mathrm{L}^{-1}\right]$ & $0.49(8 \%)$ & $0.89(6 \%)$ & $1.92(5 \%)$ & $0.24(4 \%)$ & $0.59(27 \%)$ & 2 \\
\hline $\mathrm{IC}_{50}, \mathrm{mg}$ of bioavailable $\left[\mathrm{Ag} \mathrm{L}^{-1}\right]$ & $1.52(24 \%)$ & $1.2(8 \%)$ & $1.8(4 \%)$ & $2.1(38 \%)$ & $2.4(110 \%)$ & 2 \\
\hline
\end{tabular}

the found $I C_{50}$ values shrink with changing from the added amounts of $\mathrm{Ag}$ to the released $\mathrm{Ag}^{+}$ions in medium and again to the bioavailable amounts of $\mathrm{Ag}$, converging finally at the limiting value of $2 \mathrm{mg} \mathrm{L}^{-1}$ for silver nitrate. The behavior of the positively charged BPEl-AgNPs is especially striking: $27 \%$ of the $\mathrm{Ag}$ were released as $\mathrm{Ag}^{+}$ions, but $110 \%$ were measured to be bioavailable, matching to the found high toxicity of these particles not explainable otherwise. The bioavailable amounts were higher than the dissolved amounts for all particles except for the biggest Ag-cit ${ }_{40}$ NPs.

These findings suggest that size and surface properties of the AgNPs determine how much Ag is delivered to the bacterial cells. Thus, positively charged BPEl-AgNPs adhere better to the rather negative charged bacterial cell walls. Experiments with E. coli single gene deletion strains to investigate the toxicity pathways of the different AgNPs in comparison with $\mathrm{AgNO}_{3}$ and other NPs that do not contain Ag (Figure 14) showed that some pathways seemed specific for Ag, whereas others seem to be related to a nanoparticle specific mechanism. Positively charged NPs interfered more with the bacterial electron transport and lead to increased ROS production at the cell membrane. ROS and damage of flagellar activity was found for many Ag species. Effects on the lipopolysaccharides on the outer cell membrane were rather classified as NP specific. In conclusion, the antibacterial activity is mediated to a great extent by $\mathrm{Ag}^{+}$, but also involves particle specific pathways that are highly dependent on their physicochemical properties.

In contrast to most studies, Choi and Hu found a higher toxicity of AgNPs than $\mathrm{Ag}^{+}$at equivalent $\mathrm{Ag}$ levels on nitrifying bacteria. ${ }^{[7]}$ They found a correlation of the AgNP toxicity with the amounts of intracellular ROS only for $\mathrm{Ag}<5 \mathrm{~nm}$ and supposed that the smaller AgNPs are transported more easily

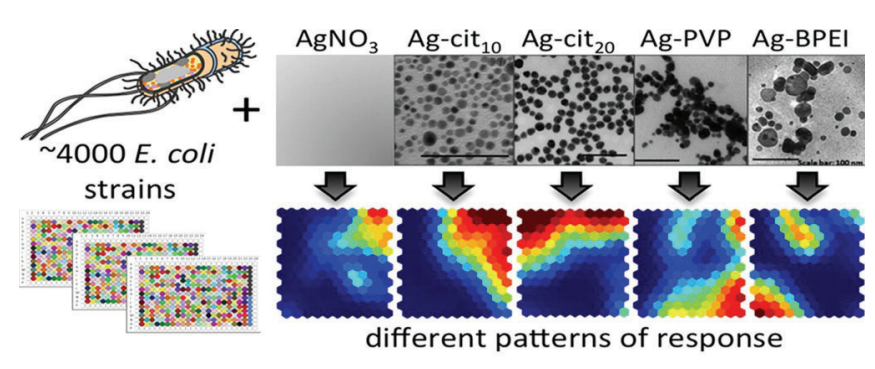

Figure 14. "Self-organizing map analysis of $E$. coli gene deletion strains that are more sensitive than the non-mutated E. coli strain to $\mathrm{AgNO}_{3}$ and the tested AgNPs. Each hexagon represents a set of gene deletion strains that respond similarly to stimuli. Ag-cit ${ }_{10}$ is the only AgNP that shows a moderate correlation with $\mathrm{AgNO}_{3}$. Reprinted with permission from ref. [152]. Copyright 2014, American Chemical Society). across the bacterial membrane. The results fit to the concept of "bioavailable" Ag as well as to the dependence on the particle properties and strain specificity emphasized by the studies of Ivask et al. and Bondarenko et al. ${ }^{[63 a, 80 b, 152]}$

For surfaces, the antimicrobial mechanism might be different than for nanosilver suspensions. Cao et al. found a good antibacterial activity, but almost no released $\mathrm{Ag}^{+}$for nano-Ag modified titanium surfaces. ${ }^{[153]}$ They proposed the formation of a micro-galvanic couple between the AgNPs and Ti, leading to proton depleted regions that could disrupt the bacterial proton electrochemical gradient, hinder their attachment and survival.

\subsection{Influence of surface chemistry}

The surface charge of AgNPs is an important particle property which is often expressed by the zeta potential as electrokinetic potential in colloidal dispersions. It depends on the synthesis pathway and the surface capping ligands and affects the colloidal stability. Exchange of surface ligands can lead to agglomeration or aggregation and thus change the released fraction. They can also influence the biological activity by changing the interaction with cellular components, which is sometimes exploited for targeting specific uptake. ${ }^{[61 d]}$ Penetration of cell organelles and therefore also higher cytotoxicity was for instance shown for gum arabic coated AgNPs and did not happen if the AgNPs were "uncoated" (hydrocarbon surface layer). ${ }^{[154]}$ Inversely, polysaccharide coated AgNPs were less toxic than hydrocarbon coated ones, suggesting a higher influence of medium or cell type. ${ }^{[89]}$ The surface charge should therefore be also determined in the biological fluids used in the experiments. For negatively charged particles, no correlation between the toxicity against Caenorhabditis elegans and the zeta potential was detected. ${ }^{[119]}$ For positively charged AgNPs, a correlation with a higher toxicity against murine macrophages and lung epithelial cells was however found, ${ }^{[141]}$ along with an enhanced bactericidal activity ${ }^{[152,155]}$ due to enhanced adhesion to the negatively charged bacterial cells. ${ }^{[156]}$ It was also shown how the adsorption of bacterial exopolysaccharides on the AgNP surface changes the zeta potential and the colloidal stability of the particles. ${ }^{[157]}$ The influence of electrostatic interactions between the bacterial cells and the particles on the toxicity was shown by altering the bactericidal activity of Ag encapsulated in mesoporous silica by changing the surface charge. ${ }^{[155 b]}$

Overall, surface ligands, and surface charge, seem to have a significant influence on the toxicity as they can modulate the bioavailability by the interaction with biological compartments 
or proteins and by altering the Ag dissolution. As the surface chemistry is changed drastically in vivo compared to in vitro experiments (due to the presence of different proteins in variable amounts for corona formation), the extrapolation of any in vitro results to the in vivo situation remains ambiguous. ${ }^{[158]}$

\subsection{Reverse reaction: Reduction of released $\mathrm{Ag}^{+}$}

Besides considerations of the dissolution mechanisms, researchers should as well focus on the possibility of the reverse reaction. Released $\mathrm{Ag}^{+}$might be reduced again to $\mathrm{Ag}^{0}$, thus forming new nanoparticles or leading to the growth of existing ones. TEM studies revealed that Ag undergoes severe changes in contact with living cells. Initially well-defined Ag colloids lost their shape and size distribution after uptake. Wildt et al. showed for instance the presence of very small AgNPs with a diameter of $<5 \mathrm{~nm}$ in L929 fibroblasts by TEM and EDX analysis. ${ }^{[63 c]}$ The formation of secondary AgNPs was also shown in vivo after administration of $\mathrm{Ag}^{+}$to rats. ${ }^{[159]}$ In 2015, Wakshlak et al. showed that silver continues to be bactericidal even if it had already killed bacterial cells. ${ }^{[160]}$ They separated the bacteria killed by $\mathrm{Ag}^{+}$from the supernatant medium and exposed them to a fresh bacterial culture. If the bacteria were killed with low amounts of $\mathrm{Ag}^{+}$, the cells were more toxic, while if higher concentrations were used, the supernatant showed a greater effect. The authors found that the amount of adsorbed $\mathrm{Ag}^{+}$to the bacterial cells fits to a Langmuir adsorption isotherm. TEM investigations revealed that the $\mathrm{Ag}^{+}$were reduced
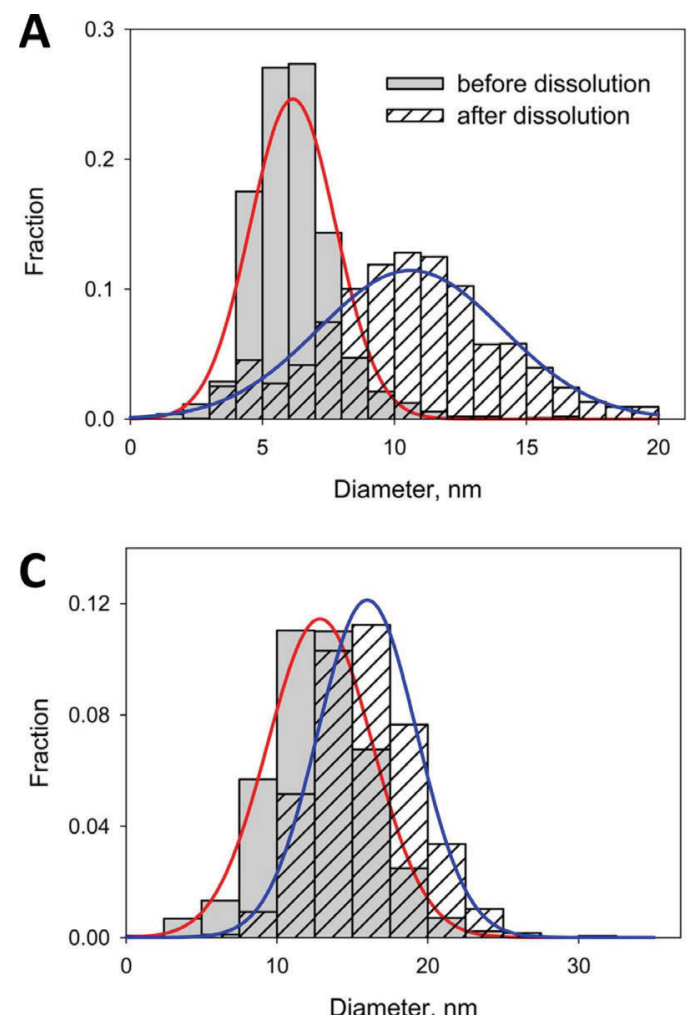

to $5-10 \mathrm{~nm}$ AgNPs that were evenly distributed in the bacterial cells, acting as Ag reservoir.

Without the presence of organic material, AgNPs are prone to changes and tend to grow in size during dissolution. ${ }^{[108]}$ Figure 15 shows the normalized size distributions before and after the dissolution of different small Ag colloids $(6-13 \mathrm{~nm})$ in ultrapure water. While larger AgNPs $(70 \mathrm{~nm})$ did not dissolve and increase in size, the authors attributed the growth of the smaller AgNPs to Ostwald ripening by oxidative dissolution followed by $\mathrm{Ag}^{+}$reduction and deposition onto the bigger particles.

$\mathrm{Yu}$ et al. studied the dissolution and reduction processes of AgNP suspensions in one experiment by using ${ }^{107} \mathrm{AgNP}$ with 99.5\% enrichment and ${ }^{109} \mathrm{AgNO}_{3}$ with $99.81 \%$ enrichment (natural abundance: 52 (107)/ 48 (109) \%). Isotope analysis enabled the tracking of the dissolution and reduction separately. No reduction of ${ }^{109} \mathrm{Ag}^{+}$was found in ultrapure water over three days even in presence of sunlight. Instead, the dissolution of ${ }^{107} \mathrm{AgNPs}$ was observed, showing a higher rate in sunlight than in dark. As soon as organic matter was added (Suwannee River humic acid, SRHA), the free $\mathrm{Ag}^{+}$was reduced to small AgNPs, again with higher rates in sunlight. At the same time, also the dissolution reaction took place, but at lower rates than without SRHA.

Glover et al. showed that only AgNPs stored under exclusion of humidity remain stable. ${ }^{[161]}$ Under ambient conditions (humidity and oxygen), $\mathrm{Ag}^{+}$ions are released and reduced again to new NPs (Figure 16). The reduction can be caused chemically or by light and was proven to happen within a few hours
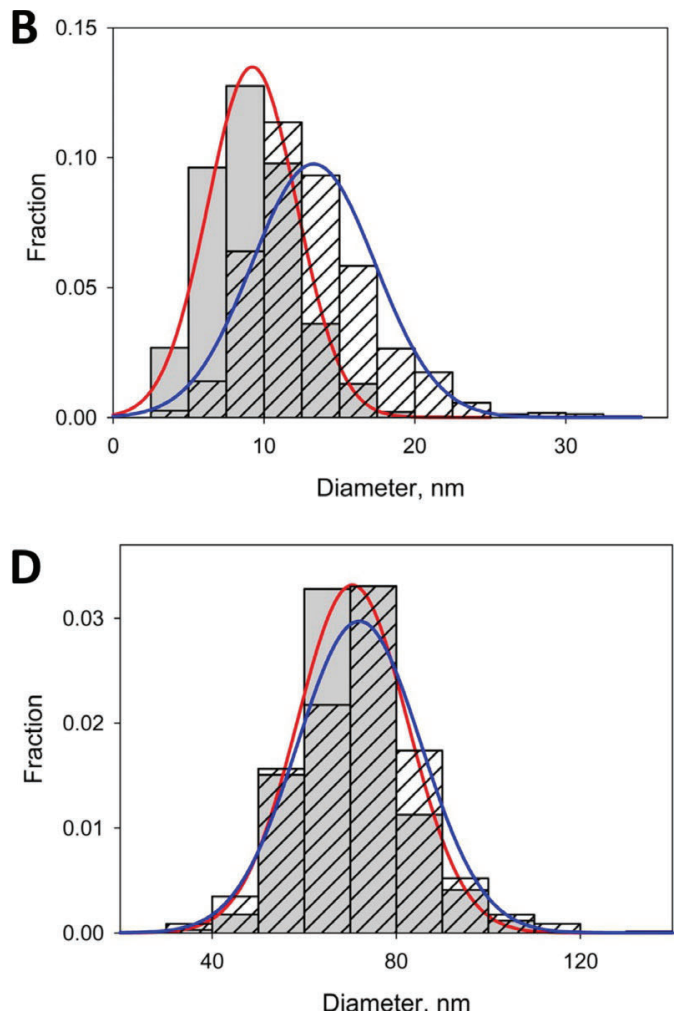

Figure 15. Normalized size distributions of AgNPs before and after dissolution experiments in ultrapure water for 80 days by TEM: (A) $6 \mathrm{~nm}$, (B) 9 nm, (C) $13 \mathrm{~nm}$, (D) $70 \mathrm{~nm}$ initial diameter. Reprinted with permission from ref. [108]. Copyright 2014, American Chemical Society. 


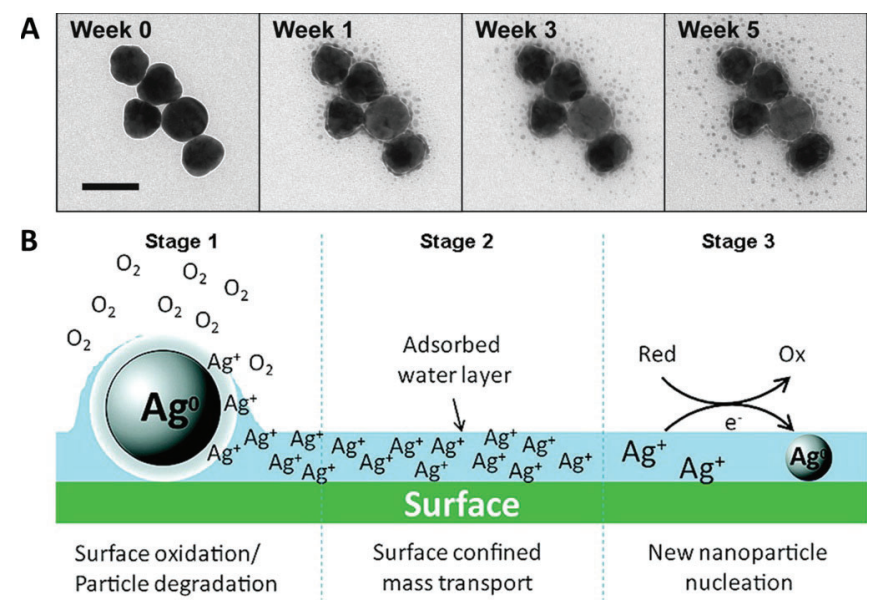

Figure 16. (A) Formation of smaller AgNPs around larger parent AgNPs over five weeks at $100 \%$ relative humidity. (B) Pathway for their formation proposed by Glover et al. Reprinted with permission from ref. [161]. Copyright 2011, American Chemical Society.

for a variety of different AgNPs by TEM imaging. Access to light extends the degree of transformation. In order to rule out that the beam of grids of the TEM investigations generated these results, the experiments were confirmed using AFM. The formation of new NPs under humid conditions was even observed for macroscopic Ag objects. As copper objects showed the same behavior, the authors concluded that the observed effect might be of general nature so that many metal objects could be a "natural" source of nanoparticles under certain environmental conditions.

Overall, it can be concluded that nanosilver undergoes significant changes upon exposure to biological or natural environments and even during simple storage, thus changing oxidation state, size, shape, and surface functionality. Hence, a detailed characterization state of a nanosilver sample is time dependent and needs to be performed at the same time and under the same conditions of any biological experiment to draw structure-function correlations. Age, storage conditions and dissolved fraction are parameters that should be reported.

\subsection{Resistance}

Bacterial resistance to silver is known since a long time, but the prevalence is still not sufficiently investigated. Clinically, a low prevalence is reported, ${ }^{[46]}$ but it is encoded on plasmids which offer easy options of transfer to other bacterial strains. ${ }^{[162]}$ Emerging silver resistance might be avoided by supplying silver amounts with high and rapid bactericidal activity. In the context of potential resistance developments, the spreading of silver use in consumer products should be handled with care as a precautionary measure.

Bacteria that developed resistance to higher $\mathrm{Ag}^{+}$concentrations in natural environments use efflux pump mechanisms and either a loss of outer membrane porins or an additional periplasmic silver-sequestration protein. ${ }^{[163]}$ Khan et al. reported the tolerance of up to $200 \mathrm{mg} \mathrm{L}^{-1}$ nanosilver by Bacillus pumilus, a sewage isolate, that "defends" itself by coating the
AgNPs with extracellular polymeric substances. Exposure of AgNPs isolated after contact with the supernatant of a B. pumilus culture to Ag sensitive control strains (E. coli, S. aureus and $M$. luteus) resulted in a reduced inhibition compared to the original "uncoated" AgNPs. ${ }^{[164]}$ For engineered, silver-tolerant E. coli, a Ag-binding peptide motif was introduced (AgBP2) and the formation of nanoparticle-like structures was observed upon Ag exposure. ${ }^{[165]}$ Pseudomonas stutzeri AG259, a silver mine strain, uses as well the mechanism of reducing $\mathrm{Ag}^{+}$to nanosilver in order to reduce the amount of bioavailable Ag. ${ }^{[46]}$

So far, resistance is only known for Gram-negative bacteria. Kuehl et al. tried in 2016 to induce resistance in seven Staphylococci strains by exposure to sublethal concentrations; ${ }^{[163 a]} 50$ consecutive passages were however not enough to result in any $\mathrm{Ag}^{+}$resistance.

Panáček et al. described a new mechanism of resistance development in Gram-negative bacteria specific towards AgNPs in 2018. ${ }^{[166]}$ This mechanism is based on the bacteria's ability to express increased levels of the protein flagellin that leads to such severe aggregation of AgNPs that they precipitate and are no longer bioavailable and toxic. The precipitation can be seen by eye and was proven by UV/Vis spectroscopy and TEM and occurred in liquid media as well as on agar plates. Flagellin was reported to be the most abundant protein in the analyzed extract from the culture medium. Addition of commercial flagellin solution induced the same aggregation behavior of the AgNPs. For inducing the resistance, the authors exposed the bacteria to subinhibitory concentrations of AgNPs and subcultured them 20 times. After each subculture, they determined the MIC, finding the values to increase slowly from about $1.7 \mathrm{mg} \mathrm{L}^{-1}$ to $>54 \mathrm{mg} \mathrm{L}^{-1}$ from the 6 th to 13 th step. Importantly the induced $\mathrm{Ag}$ resistance was reported to be a NP specific mechanism as the MIC of $\mathrm{AgNO}_{3}$ for the parent "AgNP-susceptible" strain did not differ from the final "AgNP-resistant" strain. Also, the same experimental set-up using $\mathrm{AgNO}_{3}$ instead of the AgNP could not induce resistance. Addition of pomegranate rind extract as a known flagellin inhibitor shifts the MIC back to lower concentrations. Genome sequencing for the "AgNP-resistant" and susceptible strains showed no significant changes, meaning that the resistance mechanism via flagellin expression does not require genetic changes.

Another strategy of bacteria to cope with heavy metal ions, hence also silver, is the metal ion reduction, in the case of silver to AgNP. This process can occur, for example, with anaerobic species, such as Geobacter sulfurreducens or Shewanella oneidensis, which typically reduce metal ions in the environment, either in solution or in minerals. Reduction of metal ions has been described to occur either by electron transport through pili from inside to the outside of the bacterial cell, ${ }^{[167]}$ or by transport of the electrons via c-type cytochromes through the periplasm to the outer membrane. ${ }^{[168]}$ These mechanisms allow such bacteria to cope with high levels of potentially toxic metal ions, without however being absolutely resistant. 


\section{Conclusions}

Understanding the chemistry of silver and silver nanoparticles in biological environments is far from trivial. Being a $\mathrm{d}^{10}$-metal ion, $\mathrm{Ag}^{+}$has a closed electron shell, and while it typically prefers an unusual linear coordination, the coordination number can nevertheless vary depending on the donor atoms and the ligand charge and size. The coordination of silver ions by $\mathrm{N}$-, Sand O-donor atoms of biomolecules or counter ions furthermore influences the redox properties of $\mathrm{Ag}^{+}$, and complex reaction sequences of AgNP formation and re-dissolution come into play. It is therefore crucial to know as much as possible about the experimental conditions, the chemical composition and the external factors in vitro and in vivo in order to anticipate a certain reactivity of silver in this specific environment. Some puzzle pieces are known and were described in this Review, but one must expect further unknowns that remain yet to be discovered, observed and interpreted. Experiments with silver must therefore be carried out with the required care and expertise, and observations made should be interpreted cautiously after evaluating the different possibilities of reaction. It is thus not surprising that the current literature about the use of silver in medicine may provide opposing results and many studies need to be repeated in order to complete the details about the experimental conditions. A lot remains thus to be done, following the best practices and giving as many details as possible about all factors influencing the experiments. In times of rising superbugs, silver remains thus still a hope for its antimicrobial activities are various and include many targets, therefore rendering resistance almost impossible. Understanding the chemistry of silver in medicine is thus crucial for our future.

\section{Acknowledgements}

We thank the Swiss National Science Foundation for continuous support of this research, in particular within the NCCR Bioinspired Materials and project 178827.

\section{Conflict of interest}

The authors declare no conflict of interest.

Keywords: biological medium • dissolution - microbes nanoparticles $\cdot$ silver

[1] Review on Antimicrobial Resistance: Tackling Drug-Resistant Infections Globally-Final Report and Recommendations. Wellcome Trust, UK Government, 2016.

[2] WHO, Antimicrobial resistance: global report on surveillance 2014, WHO Press, Geneva, 2014.

[3] WHO, Global action plan on antimicrobial resistance, WHO Press, Geneva, 2015, pp. 1-28.

[4] E. Y. Klein, T. P. Van Boeckel, E. M. Martinez, S. Pant, S. Gandra, S. A. Levin, H. Goossens, R. Laxminarayan, Proc. Natl. Acad. Sci. USA 2018, 115, E3463-E3470.

[5] R. Laxminarayan, P. Matsoso, S. Pant, C. Brower, J. A. Rottingen, K. Klugman, S. Davies, Lancet 2016, 387, 168-175.
[6] H. Kresse, M. J. Belsey, H. Rovini, Nat. Rev. Drug Discovery 2007, 6, 1920.

[7] A. Ivask, S. George, O. Bondarenko, A. Kahru in Nano-Antimicrobials: Progress and Prospects (Eds.: N. Cioffi, M. Rai), Springer, Heidelberg, 2012, pp. 253-290.

[8] L. Rizzello, P. P. Pompa in Silver Nanoparticles for Antibacterial Devices-Biocompatibility and Toxicity (Ed.: H. Cao), CRC Press, Boca Raton, 2017, pp. 419-441.

[9] M. Vert, Y. Doi, K.-H. Hellwich, M. Hess, P. Hodge, P. Kubisa, M. Rinaudo, F. Schué, Pure Appl. Chem. 2012, 84, 377.

[10] D. F. Williams, Biomaterials 2009, 30, 5897-5909.

[11] W. Zimmerli in Silver Nanoparticles for Antibacterial Devices: Biocompatibility and Toxicity (Ed.: H. Cao), CRC Press, Boca Raton, 2017, pp. 361 388.

[12] H. J. Busscher, H. C. van der Mei, G. Subbiahdoss, P. C. Jutte, J. J. A. M. van den Dungen, S. A. J. Zaat, M. J. Schultz, D. W. Grainger, Sci. Transl. Med. 2012, 4, 153rv10.

[13] A. G. Gristina, Science 1987, 237, 1588-1595.

[14] N. C. Roles, Proc. R. Soc. Med. 1971, 64, 636-638.

[15] a) B. Lindeque, Z. Hartman, A. Noshchenko, M. Cruse, Orthopedics 2014, 37, 257-265; b) W. Zimmerli, A. Trampuz, P. E. Ochsner, N. Engl. J. Med. 2004, 351, 1645-1654.

[16] B. A. Lipsky, J. A. Weigelt, V. Gupta, A. Killian, M. M. Peng, Infect. Control Hosp. Epidemiol. 2007, 28, 1290-1298.

[17] D. R. Osmon, E. F. Berbari, A. R. Berendt, D. Lew, W. Zimmerli, J. M. Steckelberg, N. Rao, A. Hanssen, W. R. Wilson, Clin. Infect. Dis. 2013, 56, e1-e25.

[18] S. D. Elek, P. E. Conen, Br. J. Exp. Pathol. 1957, 38, 573-586.

[19] W. Zimmerli, F. A. Waldvogel, P. Vaudaux, U. E. Nydegger, J. Infect. Dis. $1982,146,487-497$

[20] W. Zimmerli, O. Zak, K. Vosbeck, Scand. J. Infect. Dis. 1985, 17, $303-$ 310.

[21] R. H. Fitzgerald, Jr., Arch. Surg. 1979, 114, 772-775.

[22] P. M. Sethi, J. R. Sabetta, S. J. Stuek, S. V. Horine, K. B. Vadasdi, R. T. Greene, J. G. Cunningham, S. R. Miller, J. Shoulder Elbow Surg. 2015, 24, $796-803$.

[23] K.-Y. Ha, Y.-G. Chung, S.-J. Ryoo, Spine 2005, 30, 38-43.

[24] D. Hudetz, S. Ursic Hudetz, L. G. Harris, R. Luginbuhl, N. F. Friederich, R. Landmann, Clin. Microbiol. Infect. 2008, 14, 1135-1145.

[25] J. Verhoef, J. Chemother. 1991, 3, 93-97.

[26] D. G. Wright, J. I. Gallin, J. Immunol. 1979, 123, 285-294.

[27] W. Zimmerli, P. D. Lew, F. A. Waldvogel, J. Clin. Invest. 1984, 73, 1191 1200.

[28] L. Bernard, P. Vaudaux, E. Huggler, R. Stern, C. Fréhel, P. Francois, D. Lew, P. Hoffmeyer, FEMS Immunol. Med. Microbiol. 2007, 49, 425-432.

[29] R. S. Tuan, F. Y.-I. Lee, Y. Konttinen, J. M. Wilkinson, R. L. Smith, J. Am. Acad. Orthop. Surg. 2008, 16, S42-S48.

[30] J. A. Shapiro, Annu. Rev. Microbiol. 1998, 52, 81-104.

[31] J. W. Costerton, Z. Lewandowski, D. E. Caldwell, D. R. Korber, H. M. Lappin-Scott, Annu. Rev. Microbiol. 1995, 49, 711 - 745.

[32] Y.-H. Li, X. Tian, Sensors 2012, 12, 2519-2538.

[33] K. Lewis, Antimicrob. Agents Chemother. 2001, 45, 999-1007.

[34] C. A. Fux, J. W. Costerton, P. S. Stewart, P. Stoodley, Trends Microbiol. 2005, 13, 34-40.

[35] P. Wu, D. W. Grainger, Biomaterials 2006, 27, 2450-2467.

[36] R. R. Maddikeri, S. Tosatti, M. Schuler, S. Chessari, M. Textor, R. G. Richards, L. G. Harris, J. Biomed. Mater. Res. Part A 2008, 84, 425-435.

[37] S. K. Wilson, J. W. Costerton, J. Sex. Med. 2012, 9, 44-53.

[38] C. A. Broekhuizen, L. de Boer, K. Schipper, C. D. Jones, S. Quadir, C. M. Vandenbroucke-Grauls, S. A. Zaat, J. Biomed. Mater. Res. Part A 2008, $85,498-505$

[39] a) D. Yang, A. R. Wijenayaka, L. B. Solomon, S. M. Pederson, D. M. Findlay, S. P. Kidd, G. J. Atkins, mBio 2018, 9, e00415-e00418; b) M. J. Bosse, H. E. Gruber, W. K. Ramp, J. Bone Joint Surg. Am. 2005, 87, $1343-1347$; c) J. J. Boelens, J. Dankert, J. L. Murk, J. J. Weening, T. van der Poll, K. P. Dingemans, L. Koole, J. D. Laman, S. A. Zaat, J. Infect. Dis. 2000, 181, 1337-1349.

[40] J. G. Hendriks, D. Neut, J. R. van Horn, H. C. van der Mei, H. J. Busscher, Bone Joint J. 2005, 87, 272-276.

[41] a) I. C. Saldarriaga Fernández, H. J. Busscher, S. W. Metzger, D.W. Grainger, H. C. van der Mei, Biomaterials 2011, 32, 979-984; b) G. Sub- 
biahdoss, R. Kuijer, D. W. Grijpma, H. C. van der Mei, H. J. Busscher, Acta Biomater. 2009, 5, 1399-1404; c) G. Subbiahdoss, I. C. Fernandez, J. F. Domingues, R. Kuijer, H. C. van der Mei, H. J. Busscher, PLoS One 2011, 6, e24827.

[42] G. Subbiahdoss, R. Kuijer, H. J. Busscher, H. C. van der Mei, Microbiology 2010, 156, 3073-3078.

[43] B. Calderón-Jiménez, M. E. Johnson, A. R. Montoro Bustos, K. E. Murphy, M. R. Winchester, J. R. Vega Baudrit, Front. Chem. 2017, 5, 6.

[44] E. Meng, Q. Zhang, F. Li, T. S. Peretyazhko in Silver Nanoparticles for Antibacterial Devices: Biocompatibility and Toxicity (Ed.: H. Cao), CRC Press, Taylor \& Francis Group, Boca Raton, 2017, pp. 135-163.

[45] S. Kittler, C. Greulich, J. Diendorf, M. Köller, M. Epple, Chem. Mater. 2010, 22, 4548-4554.

[46] B. Reidy, A. Haase, A. Luch, K. A. Dawson, I. Lynch, Materials 2013, 6, $2295-2350$.

[47] TheSilverInstitute, Silver Institute Publications 2017, 1 - 4.

[48] T. M. Benn, P. Westerhoff, Environ. Sci. Technol. 2008, 42, 4133-4139.

[49] J. Farkas, H. Peter, P. Christian, J. A. Gallego Urrea, M. Hassellov, J. Tuoriniemi, S. Gustafsson, E. Olsson, K. Hylland, K. V. Thomas, Environ. Int. 2011, 37, 1057-1062.

[50] R. Kaegi, B. Sinnet, S. Zuleeg, H. Hagendorfer, E. Mueller, R. Vonbank, M. Boller, M. Burkhardt, Environ. Pollut. 2010, 158, 2900-2905.

[51] C. Lorenz, H. Hagendorfer, N. von Goetz, R. Kaegi, R. Gehrig, A. Ulrich, M. Scheringer, K. Hungerbühler, J. Nanopart. Res. 2011, 13, 3377-3391.

[52] S. W. P. Wijnhoven, W. J. G. M. Peijnenburg, C. A. Herberts, W. I. Hagens, A. G. Oomen, E. H. W. Heugens, B. Roszek, J. Bisschops, I. Gosens, D. Van De Meent, S. Dekkers, W. H. De Jong, M. van Zijverden, A. J. A. M. Sips, R. E. Geertsma, Nanotoxicology 2009, 3, 109-138.

[53] E. Vlachou, E. Chipp, E. Shale, Y. T. Wilson, R. Papini, N. S. Moiemen, Burns 2007, 33, 979-985.

[54] M. Rai, S. D. Deshmukh, A. P. Ingle, I. R. Gupta, M. Galdiero, S. Galdiero, Crit. Rev. Microbiol. 2016, 42, 46-56.

[55] J. A. Garza-Cervantes, A. Chavez-Reyes, E. C. Castillo, G. Garcia-Rivas, O. A. Ortega-Rivera, E. Salinas, M. Ortiz-Martinez, S. L. Gomez-Flores, J. A. Pena-Martinez, A. Pepi-Molina, M. T. Trevino-Gonzalez, X. Zarate, M. E. Cantu-Cardenas, C. E. Escarcega-Gonzalez, J. R. Morones-Ramirez, Sci. Rep. 2017, 7, 903.

[56] J. W. Alexander, Surg. Infect. 2009, 10, 289-292.

[57] B. Nowack, H. F. Krug, M. Height, Environ. Sci. Technol. 2011, 45, 11771183.

[58] S. Eckhardt, P. S. Brunetto, J. Gagnon, M. Priebe, B. Giese, K. M. Fromm, Chem. Rev. 2013, 113, 4708-4754.

[59] H. Zhang, M. Wu, A. Sen in Nano-Antimicrobials: Progress and Prospects (Eds.: N. Cioffi, M. Rai), Springer, Berlin, Heidelberg, 2012, pp. 3-45.

[60] K. K. Y. Wong, X. Liu, Med. Chem. Commun. 2010, 1, 125-131.

[61] a) J. Helmlinger, C. Sengstock, C. Groß-Heitfeld, C. Mayer, T. A. Schildhauer, M. Köller, M. Epple, RSC Adv. 2016, 6, 18490-18501; b) J. Liu, D. A. Sonshine, S. Shervani, R. H. Hurt, ACS Nano 2010, 4, 6903-6913; c) N. Durán, M. Durán, M. B. de Jesus, A. B. Seabra, W. J. Favaro, G. Nakazato, Nanomedicine 2016, 12, 789-799; d) R. Foldbjerg, X. Jiang, T. Miclăuş, C. Chen, H. Autrup, C. Beer, Toxicol. Res. 2015, 4, 563-575.

[62] a) L. K. Limbach, R. N. Grass, W. J. Stark, Chimia 2009, 63, 38-43; b) E. J. Park, J. Yi, Y. Kim, K. Choi, K. Park, Toxicol. In Vitro 2010, 24, 872-878.

[63] a) O. Bondarenko, A. Ivask, A. Kakinen, I. Kurvet, A. Kahru, PLoS One 2013, 8, e64060; b) I. L. Hsiao, Y. K. Hsieh, C. F. Wang, I. C. Chen, Y. J. Huang, Environ. Sci. Technol. 2015, 49, 3813-3821; c) B. E. Wildt, A. Celedon, E. I. Maurer, B. J. Casey, A. M. Nagy, S. M. Hussain, P. L. Goering, Nanotoxicology 2016, 10, 710-719.

[64] E. D. Cavassin, L. F. de Figueiredo, J. P. Otoch, M. M. Seckler, R. A. de Oliveira, F. F. Franco, V. S. Marangoni, V. Zucolotto, A. S. Levin, S. F. Costa, J. Nanobiotechnol. 2015, 13, 64.

[65] M. K. Rai, S. D. Deshmukh, A. P. Ingle, A. K. Gade, J. Appl. Microbiol. 2012, 112, $841-852$.

[66] a) M. Rai, A. Yadav, N. Cioffi in Nano-Antimicrobials: Progress and Prospects (Eds.: N. Cioffi, M. Rai), Springer, Berlin, Heidelberg, 2012, pp. 211-224; b) S. Sütterlin, E. Tano, A. Bergsten, A. B. Tallberg, A. Melhus, Acta Derm.-Venereol. 2012, 92, 34-39.

[67] Q. L. Feng, J. Wu, G. Q. Chen, F. Z. Cui, T. N. Kim, J. O. Kim, J. Biomed. Mater. 2000, 52, 662-668.

[68] S. Chernousova, M. Epple, Angew. Chem. Int. Ed. 2013, 52, 1636-1653; Angew. Chem. 2013, 125, 1678-1696.
[69] a) M. Rai, A. Yadav, A. Gade, Biotechnol. Adv. 2009, 27, 76-83; b) C. Marambio-Jones, E. M. V. Hoek, J. Nanopart. Res. 2010, 12, $1531-1551$; c) A. Kedziora, M. Speruda, E. Krzyzewska, J. Rybka, A. Lukowiak, G. Bugla-Ploskonska, Int. J. Mol. Sci. 2018, 19, 444.

[70] a) A. D. Russell, W. B. Hugo, Prog. Med. Chem. 1994, 31, 351-370; b) P. D. Bragg, D. J. Rainnie, Can. J. Microbiol. 1974, 20, $883-889$.

[71] C.-N. Lok, C.-M. Ho, R. Chen, Q.-Y. He, W.-Y. Yu, H. Sun, P. K.-H. Tam, J.-F. Chiu, C.-M. Che, J. Proteome Res. 2006, 5, 916-924.

[72] F. Mirzajani, A. Ghassempour, A. Aliahmadi, M. A. Esmaeili, Res. Microbiol. 2011, 162, 542-549.

[73] Z. M. Xiu, Q. B. Zhang, H. L. Puppala, V. L. Colvin, P. J. Alvarez, Nano Lett. 2012, 12, $4271-4275$.

[74] M. Yamanaka, K. Hara, J. Kudo, Appl. Environ. 2005, 71, 7589-7593.

[75] a) W. R. Li, X. B. Xie, Q. S. Shi, S. S. Duan, Y. S. Ouyang, Y. B. Chen, Biometals 2011, 24, 135-141; b) Y. J. Lee, J. Kim, J. Oh, S. Bae, S. Lee, I. S. Hong, S. H. Kim, Environ. Toxicol. Chem. 2012, 31, 155-159.

[76] a) H. J. Park, J. Y. Kim, J. Kim, J. H. Lee, J. S. Hahn, M. B. Gu, J. Yoon, Water Res. 2009, 43, 1027-1032; b) O. Gordon, T. Vig Slenters, P. S. Brunetto, A. E. Villaruz, D. E. Sturdevant, M. Otto, R. Landmann, K. M. Fromm, Antimicrob. Agents Chemother. 2010, 54, 4208-4218.

[77] O. Choi, Z. Hu, Environ. Sci. Technol. 2008, 42, 4583-4588.

[78] J. S. Kim, E. Kuk, K. N. Yu, J.-H. Kim, S. J. Park, H. J. Lee, S. H. Kim, Y. K. Park, Y. H. Park, C.-Y. Hwang, Y.-K. Kim, Y.-S. Lee, D. H. Jeong, M.-H. Cho, Nanomedicine 2007, 3, 95-101.

[79] a) L. A. Tamayo, P. A. Zapata, N. D. Vejar, M. I. Azócar, M. A. Gulppi, X. Zhou, G. E. Thompson, F. M. Rabagliati, M. A. Páez, Mater. Sci. Eng. C 2014, 40, 24-31; b) W. K. Jung, H. C. Koo, K. W. Kim, S. Shin, S. H. Kim, Y. H. Park, Appl. Environ. 2008, 74, $2171-2178$.

[80] a) G. A. Sotiriou, S. E. Pratsinis, Environ. Sci. Technol. 2010, 44, 56495654; b) A. Ivask, I. Kurvet, K. Kasemets, I. Blinova, V. Aruoja, S. Suppi, H. Vija, A. Kakinen, T. Titma, M. Heinlaan, M. Visnapuu, D. Koller, V. Kisand, A. Kahru, PLoS One 2014, 9, e102108.

[81] J. H. Ji, J. H. Jung, S. S. Kim, J. U. Yoon, J. D. Park, B. S. Choi, Y. H. Chung, I. H. Kwon, J. Jeong, B. S. Han, J. H. Shin, J. H. Sung, K. S. Song, I. J. Yu, Inhalation Toxicol. 2007, 19, 857-871.

[82] H. S. Sharma, S. F. Ali, S. M. Hussain, J. J. Schlager, A. Sharma, J. Nanosci. Nanotechnol. 2009, 9, 5055-5072.

[83] D. P. Lankveld, A. G. Oomen, P. Krystek, A. Neigh, A. Troost De Jong, C. W. Noorlander, J. C. Van Eijkeren, R. E. Geertsma, W. H. De Jong, Biomaterials 2010, 31, 8350-8361.

[84] J. H. Shannahan, R. Podila, A. A. Aldossari, H. Emerson, B. A. Powell, P. C. Ke, A. M. Rao, J. M. Brown, Toxicol. Sci. 2015, 143, 136-146.

[85] J. Kaur, K. Tikoo, Food Chem. 2013, 51, 1-14.

[86] R. P. Singh, P. Ramarao, Toxicol. Lett. 2012, 213, 249-259.

[87] S. Grosse, L. Evje, T. Syversen, Toxicol. In Vitro 2013, 27, 305-313.

[88] I. Sur, M. Altunbek, M. Kahraman, M. Culha, Nanotechnology 2012, 23, 375102.

[89] L. K. Braydich-Stolle, B. Lucas, A. Schrand, R. C. Murdock, T. Lee, J. J. Schlager, S. M. Hussain, M. C. Hofmann, Toxicol. Sci. 2010, 116, 577589.

[90] P. V. Asharani, M. P. Hande, S. Valiyaveettil, BMC Cell Biol. 2009, 10, 65.

[91] L. A. Austin, B. Kang, C. W. Yen, M. A. El-Sayed, Bioconjugate Chem. 2011, 22, 2324-2331.

[92] C. W. Yen, M. A. Mahmoud, M. A. El-Sayed, J. Phys. Chem. A 2009, 113, $4340-4345$.

[93] W. J. Trickler, S. M. Lantz, R. C. Murdock, A. M. Schrand, B. L. Robinson, G. D. Newport, J. J. Schlager, S. J. Oldenburg, M. G. Paule, W. Slikker Jr., S. M. Hussain, S. F. Ali, Toxicol. Sci. 2010, 118, 160-170.

[94] A. Bianchini, M. Grosell, S. M. Gregory, C. M. Wood, Environ. Sci. Technol. 2002, 36, 1763-1766.

[95] a) Z.-H. Jiao, M. Li, Y.-X. Feng, J.-C. Shi, J. Zhang, B. Shao, PLoS One 2014, 9, e102564; b) S.-H. Shin, M.-K. Ye, H.-S. Kim, H.-S. Kang, Int. Immunopharmacol. 2007, 7, 1813-1818; c) M. M. Sthijns, W. Thongkam, C. Albrecht, B. Hellack, A. Bast, G. R. Haenen, R. P. Schins, Toxicol. In Vitro 2017, 40, 223-233.

[96] S. Shrivastava, S. K. Singh, A. Mukhopadhyay, A. S. K. Sinha, R. K. Mandal, D. Dash, Colloids Surf. B 2011, 82, 241-246.

[97] S. Galdiero, A. Falanga, M. Vitiello, M. Cantisani, V. Marra, M. Galdiero, Molecules 2011, 16, 8894-8918.

[98] C. E. Albers, W. Hofstetter, K. A. Siebenrock, R. Landmann, F. M. Klenke, Nanotoxicology 2013, 7, 30-36. 
[99] C. Greulich, D. Braun, A. Peetsch, J. Diendorf, B. Siebers, M. Epple, M. Köller, RSC Adv. 2012, 2, 6981.

[100] J. Jain, S. Arora, J. M. Rajwade, P. Omray, S. Khandelwal, K. M. Paknikar, Mol. Pharm. 2009, 6, 1388-1401.

[101] T. Hrkac, C. Rohl, R. Podschun, V. Zaporojtchenko, T. Strunskus, H. Papavlassopoulos, D. Garbe-Schonberg, F. Faupel, Mater. Sci. Eng. C 2013, 33, 2367- 2375

[102] S. Agnihotri, S. Mukherji, S. Mukherji, Nanoscale 2013, 5, 7328-7340.

[103] J. P. Kaiser, M. Roesslein, L. Diener, A. Wichser, B. Nowack, P. Wick, J. Nanobiotechnol. 2017, 15, 5.

[104] J. Zook, S. E. Long, D. Cleveland, C. Lay, A. Geronimo, R. Maccuspie, Anal. Bioanal. Chem. 2011, 401, 1993-2002.

[105] a) G. A. Sotiriou, A. Meyer, J. T. Knijnenburg, S. Panke, S. E. Pratsinis, Langmuir 2012, 28, 15929-15936; b) C. Levard, E. M. Hotze, G. V. Lowry, G. E. Brown, Jr., Environ. Sci. Technol. 2012, 46, 6900-6914; c) C. M. Ho, S. K. Yau, C. N. Lok, M. H. So, C. M. Che, Chem. Asian J. 2010, 5, 285-293.

[106] J. Liu, R. H. Hurt, Environ. Sci. Technol. 2010, 44, 2169-2175.

[107] X. Li, J. J. Lenhart, H. W. Walker, Langmuir 2012, 28, 1095-1104.

[108] T. S. Peretyazhko, Q. Zhang, V. L. Colvin, Environ. Sci. Technol. 2014, 48, $11954-11961$.

[109] K. Loza, J. Diendorf, C. Sengstock, L. Ruiz-Gonzalez, J. M. GonzalezCalbet, M. Vallet-Regi, M. Köller, M. Epple, J. Mater. Chem. B 2014, 2, 1634.

[110] B. Molleman, T. Hiemstra, Langmuir 2015, 31, 13361-13372.

[111] B. Molleman, T. Hiemstra, Environ. Sci. Nano 2017, 4, 1314-1327.

[112] R. Ma, C. Levard, J. D. Judy, J. M. Unrine, M. Durenkamp, B. Martin, B. Jefferson, G. V. Lowry, Environ. Sci. Technol. 2014, 48, 104-112.

[113] C. Levard, S. Mitra, T. Yang, A. D. Jew, A. R. Badireddy, G. V. Lowry, G. E. Brown, Jr., Environ. Sci. Technol. 2013, 47, 5738-5745.

[114] N. W. H. Adams, J. R. Kramer, Environ. Toxicol. Chem. 1999, 18, 2667 2673.

[115] R. Kaegi, A. Voegelin, B. Sinnet, S. Zuleeg, H. Hagendorfer, M. Burkhardt, H. Siegrist, Environ. Sci. Technol. 2011, 45, 3902-3908.

[116] J. Liu, Z. Wang, F. D. Liu, A. B. Kane, R. H. Hurt, ACS Nano 2012, 6, 9887-9899.

[117] R. A. Bell, J. R. Kramer, Environ. Toxicol. Chem. 1999, 18, 9-22.

[118] M. Marchioni, T. Gallon, I. Worms, P.-H. Jouneau, C. Lebrun, G. Veronesi, D. Truffier-Boutry, E. Mintz, P. Delangle, A. Deniaud, I. Michaud-Soret, Environ. Sci. Nano 2018, 5, $1911-1920$.

[119] X. Yang, A. P. Gondikas, S. M. Marinakos, M. Auffan, J. Liu, H. Hsu-Kim, J. N. Meyer, Environ. Sci. Technol. 2012, 46, 1119-1127.

[120] I. Lynch, K. A. Dawson, Nano Today 2008, 3, 40-47.

[121] J. H. Shannahan, X. Lai, P. C. Ke, R. Podila, J. M. Brown, F. A. Witzmann, PLoS One 2013, 8, e74001.

[122] M. Levak, P. Buric, M. Dutour Sikiric, D. Domazet Jurasin, N. Mikac, N Bacic, R. Drexel, F. Meier, Z. Jaksic, D. M. Lyons, Environ. Sci. Technol. 2017, 51, 1259-1266.

[123] C. M. Powers, A. R. Badireddy, I. T. Ryde, F. J. Seidler, T. A. Slotkin, Environ. Health Perspect. 2011, 119, 37-44.

[124] P. L. Drake, K. J. Hazelwood, Ann. Occup. Hyg. 2005, 49, 575-585.

[125] L. V. Stebounova, E. Guio, V. H. Grassian, J. Nanopart. Res. 2011, 13, $233-244$.

[126] X. Jiang, T. Miclăuş, L. Wang, R. Foldbjerg, D. S. Sutherland, H. Autrup, C. Chen, C. Beer, Nanotoxicology 2015, 9, 181-189.

[127] N. Joshi, B. T. Ngwenya, I. B. Butler, C. E. French, J. Hazard. Mater. 2015 $287,51-58$

[128] Y. H. Hsueh, K. S. Lin, W. J. Ke, C. T. Hsieh, C. L. Chiang, D. Y. Tzou, S. T. Liu, PLoS One 2015, 10, e0144306.

[129] V. De Matteis, M. A. Malvindi, A. Galeone, V. Brunetti, E. De Luca, S. Kote, P. Kshirsagar, S. Sabella, G. Bardi, P. P. Pompa, Nanomedicine 2015, 11, 731-739.

[130] a) G. Veronesi, A. Deniaud, T. Gallon, P. H. Jouneau, J. Villanova, P. Delangle, M. Carriere, I. Kieffer, P. Charbonnier, E. Mintz, I. Michaud-Soret, Nanoscale 2016, 8, 17012-17021; b) G. Veronesi, C. Aude-Garcia, I. Kieffer, T. Gallon, P. Delangle, N. Herlin-Boime, T. Rabilloud, M. Carriere, Nanoscale 2015, 7, 7323-7330.

[131] G. Hartmann, C. Hutterer, M. Schuster, J. Anal. At. Spectrom. 2013, 28, 567.

[132] S. Yu, Y. Yin, X. Zhou, L. Dong, J. Liu, Environ. Sci. Nano 2016, 3, $883-$ 893.
[133] W. Slavin, G. R. Carnrick, D. C. Manning, Anal. Chem. 1984, 56, $163-$ 168.

[134] a) J.-B. Chao, J.-F. Liu, S.-J. Yu, Y.-D. Feng, Z.-Q. Tan, R. Liu, Y.-G. Yin, Anal. Chem. 2011, 83, 6875-6882; b) S.-J. Yu, J.-B. Chao, J. Sun, Y.-G. Yin, J.-F. Liu, G.-B. Jiang, Environ. Sci. Technol. 2013, 47, 3268-3274.

[135] M. Hu, J. Fan, J. Cao, K. Song, H. Zhang, S. Sun, X. Peng, Analyst 2012, $137,2107-2111$.

[136] A. Ivask, T. Rolova, A. Kahru, BMC Biotechnol. 2009, 9, 41.

[137] R. Foldbjerg, D. A. Dang, H. Autrup, Arch. Toxicol. 2011, 85, 743-750.

[138] H. Bouwmeester, J. Poortman, R. J. Peters, E. Wijma, E. Kramer, S. Makama, K. Puspitaninganindita, H. J.P. Marvin, A. A. C. M. Peijnenburg, P. J. M. Hendriksen, ACS Nano 2011, 5, 4091 -4103.

[139] R. Foldbjerg, E. S. Irving, Y. Hayashi, D. S. Sutherland, K. Thorsen, H. Autrup, C. Beer, Toxicol. Sci. 2012, 130, 145-157.

[140] C. Beer, R. Foldbjerg, Y. Hayashi, D. S. Sutherland, H. Autrup, Toxicol. Lett. 2012, 208, 286-292.

[141] A. K. Suresh, D. A. Pelletier, W. Wang, J. L. Morrell-Falvey, B. Gu, M. J. Doktycz, Langmuir 2012, 28, 2727-2735.

[142] S. Kim, J. E. Choi, J. Choi, K. H. Chung, K. Park, J. Yi, D. Y. Ryu, Toxicol. In Vitro 2009, 23, 1076-1084.

[143] D. Guo, L. Zhu, Z. Huang, H. Zhou, Y. Ge, W. Ma, J. Wu, X. Zhang, X. Zhou, Y. Zhang, Y. Zhao, N. Gu, Biomaterials 2013, 34, 7884-7894.

[144] N. Hérault, J. Wagner, S. L. Abram, J. Widmer, L. Horvàth, D. Vanhecke, C. Bourquin, K. M. Fromm, Int. J. Nanomedicine 2020, 15, 1267-1281.

[145] W. Zhang, B. Xiao, T. Fang, Chemosphere 2018, 191, 324-334.

[146] E. Navarro, F. Piccapietra, B. Wagner, F. Marconi, R. Kaegi, N. Odzak, L. Sigg, R. Behra, Environ. Sci. Technol. 2008, 42, 8959-8964.

[147] C. Hogstrand, C. M. Wood, Environ. Toxicol. Chem. 1998, 17, 547-561.

[148] S. Y. Liau, D. C. Read, W. J. Pugh, J. R. Furr, A. D. Russell, Lett. Appl. Microbiol. 1997, 25, 279-283.

[149] X. Jin, M. Li, J. Wang, C. Marambio-Jones, F. Peng, X. Huang, R. Damoiseaux, E. M. V. Hoek, Environ. Sci. Technol. 2010, 44, 7321 - 7328.

[150] C. Gunawan, W. Y. Teoh, C. P. Marquis, J. Lifia, R. Amal, Small 2009, 5, $341-344$.

[151] J. S. McQuillan, H. G. Infante, E. Stokes, A. M. Shaw, Nanotoxicology 2012, 6, 857-866.

[152] A. Ivask, A. ElBadawy, C. Kaweeteerawat, D. Boren, H. Fischer, Z. Ji, C. H. Chang, R. Liu, T. Tolaymat, D. Telesca, J. I. Zink, Y. Cohen, P. A. Holden, H. A. Godwin, ACS Nano 2014, 8, 374-386.

[153] H. Cao, X. Liu, F. Meng, P. K. Chu, Biomaterials 2011, 32, 693-705.

[154] M. Ahamed, M. Karns, M. Goodson, J. Rowe, S. M. Hussain, J. J. Schlager, Y. Hong, Toxicol. Appl. Pharmacol. 2008, 233, 404-410.

[155] a) S. S. Khan, A. Mukherjee, N. Chandrasekaran, Colloids Surf. B 2011, $87,129-138$; b) M. Liong, B. France, K. A. Bradley, J. I. Zink, Adv. Mater. 2009, 21, 1684- 1689.

[156] E. Kłodzińska, M. Szumski, E. Dziubakiewicz, K. Hrynkiewicz, E. Skwarek, W. Janusz, B. Buszewski, Electrophoresis 2010, 31, 1590-1596.

[157] S. S. Khan, A. Mukherjee, N. Chandrasekaran, Water Res. 2011, 45 5184-5190.

[158] M. P. Monopoli, C. Aberg, A. Salvati, K. A. Dawson, Nat. Nanotechnol. 2012, 7, 779-786.

[159] M. van der Zande, R. J. Vandebriel, E. Van Doren, E. Kramer, Z. Herrera Rivera, C. S. Serrano-Rojero, E. R. Gremmer, J. Mast, R. J. B. Peters, P. C. H. Hollman, P. J. M. Hendriksen, H. J. P. Marvin, A. A. C. M. Peijnenburg, H. Bouwmeester, ACS Nano 2012, 6, 7427-7442.

[160] R. B. Wakshlak, R. Pedahzur, D. Avnir, Sci. Rep. 2015, 5, 9555.

[161] R. D. Glover, J. M. Miller, J. E. Hutchison, ACS Nano 2011, 5, 8950-8957.

[162] S. Silver, FEMS Microbiol. Rev. 2003, 27, 341-353.

[163] a) R. Kuehl, P. S. Brunetto, A. K. Woischnig, M. Varisco, Z. Rajacic, J. Vosbeck, L. Terracciano, K. M. Fromm, N. Khanna, Antimicrob. Agents Chemother. 2016, 60, 2467-2475; b) C. P. Randall, A. Gupta, N. Jackson, D. Busse, A. J. O'Neill, J. Antimicrob. Chemother. 2015, 70, 1037-1046.

[164] S. Khan, A. Mukherjee, N. Chandrasekaran, J. Environ. Sci. 2011, 23, $346-352$.

[165] R. Hall Sedlak, M. Hnilova, C. Grosh, H. Fong, F. Baneyx, D. Schwartz, M. Sarikaya, C. Tamerler, B. Traxler, Appl. Environ. 2012, 78, 2289-2296.

[166] A. Panáček, L. Kvitek, M. Smekalova, R. Vecerova, M. Kolar, M. Roderova, F. Dycka, M. Sebela, R. Prucek, O. Tomanec, R. Zboril, Nat. Nanotechnol. 2018, 13, 65-71.

[167] a) D. R. Lovley, Biochem. Soc. Trans. 2012, 40, 1186-1190; b) D. R. Lovley, D. J. F. Walker, Frontiers Microbiol. 2019, 10, 2078. 
[168] a) N. Law, S. Ansari, F. R. Livens, J. C. Renshaw, J. R. Lloyd, Appl. Environ. Microbiol. 2008, 74, 7090-7093; b) V. Chabert, L. Babel, M. P. Füeg, M. Karamash, E. S. Madivoli, N. Herault, J. M. Dantas, C. A. Salgueiro, B.
Giese, K. M. Fromm, Angew. Chem. Int. Ed. 2020, 59, 12331-12336; Angew. Chem. 2020, 132, $12430-12435$. 